\title{
THE UNCERTAINTY OF ATMOSPHERIC \\ SOURCE-RECEPTOR RELATIONSHIPS IN EUROPE
}

Joseph Alcamo and Jerzy Bartnicki

International Institute for Applied Systems Analysis,

Laxenburg, Austria

RR-91-2

February 1991

Reprinted from Atmospheric Environment Vol. 24A, No. 8, pp. 2169-2189, 1990.

INTERNATIONAL INSTITUTE FOR APPLIED SYSTEMS ANALYSIS

Laxenburg, Austria 
Research Reports, which record research conducted at IIASA, are independently reviewed before publication. However, the views and opinions they express are not necessarily those of the Institute or the National Member Organizations that support it.

Reprinted with permission from Atmospheric Environment Vol. 24A, No. 8, pp. 2169-2189, 1990.

Copyright (C)1990 Pergamon Press plc.

All rights reserved. No part of this publication may be reproduced or transmitted in any form or by any means, electronic or mechanical, including photocopy, recording, or any information storage or retrieval system, without permission in writing from the copyright holder.

Printed by Novographic, Vienna, Austria 


\section{Foreword}

This Research Report represents the culmination of an extensive analysis of the uncertainties in the relationships between emissions in one part of Europe and acidic depostion in another, as estimated by the Regional Acidification INformation and Simulation (RAINS) model developed at IIASA. These source-receptor relationships, as they are called, are derived from the calculations of the EMEP model of the Norwegian Meteorological Institute under the aegis of the UN-ECE Convention on Long-Range Transbounday Air Pollution. Both models form an important part of the scientific basis for developing new protocols for sulphur and nitrogen emission reductions in Europe to reduce further damage to the environment from acidic deposition. In this regard, it is essential to know what effect the uncertainty in source-receptor relationships will have upon developing and assessing new emission reduction strategies. For this reason, this analysis is an extremely important part of IIASA's support of the UN-ECE activities.

RODERICK SHAW

Leader

Transboundary Air Pollution Project
BO DÖÖS

Leader

Environment Program 


\title{
THE UNCERTAINTY OF ATMOSPHERIC SOURCE-RECEPTOR RELATIONSHIPS IN EUROPE
}

\author{
Joseph Alcamo and Jerzy Bartnicki* \\ International Institute for Applied Systems Analysis, A-2361 Laxenburg, Austria
}

(First received 22 December 1988 and received for publication 31 January 1990)

\begin{abstract}
This paper investigates the composite uncertainty of a long range transport model of sulfur in Europe. This composite uncertainty includes the effect on model output of uncertain transport wind, meteorological forcing functions, parameters, and spatial distribution of emissions. Other sources of uncertainty are omitted in the analysis. Stochastic simulation is used for computations. The combined effect of these uncertainties on total annual sulfur deposition at three receptors ranged from about 10 to $20 \%$ (coefficient of variation). In comparing the effects of different uncertainties on annual model output, meteorological forcing functions were found to be the least important because of their frequent temporal variation in the model.

The stochastic procedure was also used to compute the uncertainty of transfer coefficients for 30 source-receptor combinations; their relative uncertainty ranged from about 10 to $30 \%$ and was not correlated with distance. However, their absolute uncertainty (standard deviation) was strongly correlated with distance and was found to be proportional to the values of the transfer coefficients themselves. This insight was used to develop a simple method for estimating the uncertainty of sulfur deposition calculated with a transfer matrix. This method was then used to evaluate the 'reliability' of emission reduction scenarios in reducing deposition.
\end{abstract}

Key word index: Error analysis, long range transport, model evaluation, source-receptor relationships, sulfur deposition, uncertainty.

\section{INTRODUCTION}

As atmospheric models have become more frequently used in scientific research and policy analysis, more attention has also been given to their uncertainty. Progress has been made recently in quantifying this uncertainty. These efforts have taken two separate paths-one approach is to identify the discrepancy between model output and measurements. Effort has been devoted to improving statistical techniques of these comparisons (see, e.g. Dennis, 1985; Munn et al., 1987). This approach can be used to quantify uncertainty of model results of past or present conditions when measurements are available, but it cannot be used to estimate the uncertainty of future conditions when emission scenarios are changed.

In the second approach, mathematical and numerical techniques are used to compute the uncertainty of model calculations (e.g. Derwent, 1987; Alcamo and Bartnicki, 1987). In this approach model inputs are first assigned uncertainties in the form of frequency distributions or variances; these uncertainties are propagated through model equations and produce output uncertainties also in the form of frequency distributions or variance estimates. Using this approach, we can estimate uncertainty of specific source-receptor relationships and subsequently can also evaluate the uncertainty of model calculations for future emission

* On leave from the Institute of Meteorology and Water Management in Warsaw. scenarios. This second approach has been used much more extensively in water research than in the atmospheric sciences (e.g. Beck, 1988). In this paper we focus on the second approach, though it is important to note at this point that this approach is only worthwhile if the first approach has already been applied to verify the model, i.e. comparing model output to measurements should always precede mathematical uncertainty analysis.

To this point investigators using the second approach have mostly focused on particular types of uncertainty, such as parameter (e.g. Alcamo and Bartnicki, 1987), or interannual meteorology (e.g. Streets et al., 1986; Niemann, 1988). While these studies have improved our understanding of the relative importance of different uncertainties, they have not tried to comprehensively estimate model output uncertainty. Furthermore, they have not extended their work to include the use of uncertainty information in routine, policy-oriented calculations. The objectives of this paper are, first, to quantify composite uncertainty, i.e. the combined effect of several types of model uncertainty including parameters, emissions, and meteorology and, second, to derive a method for using this information in routine calculations of $\mathrm{S}$ deposition.

The framework for this analysis was presented by the authors in Alcamo and Bartnicki (1987). This framework was used to outline an uncertainty analysis for the EMEP I model of sulfur long range transport (LRT) in Europe, and to quantify parameter uncertainty in that model. Readers are referred to that 
publication for discussion of our general approach to uncertainty analysis. In the current study, we build on our previous work to more comprehensively quantify uncertainty in the EMEP II model. This model was developed by A. Eliassen and J. Saltbones at the Institute of Meteorology in Oslo under the auspices of the European Monitoring and Evaluation Program (EMEP) of the U.N. Economic Commission for Europe Convention on Transboundary Air Pollution. An early version of the model is described in OECD (1979) and Eliassen and Saltbones (1983). The most recent documentation of model equations is given in Eliassen et al. (1988), and we summarize model equations in Appendix A.

Our study concentrates on the uncertainty of using a source-receptor transfer matrix derived from a LRT model for analyzing the effect of country emissions on deposition at different locations in Europe. Therefore, the spatial scales of interest are countries as $\mathrm{SO}_{2}$ sources and grid elements as sulfur receptors.

We begin the paper by briefly describing the method of analysis and proceed to quantify the effect of specific uncertainties (parameter, wind, etc.) on various source-receptor combinations. Next we examine the composite effect of these uncertainties on the same source-receptor combinations. Following that, we look at the effect of several countries, and composite uncertainties, on particular receptors. From these model experiments we derive a method to routinely calculate uncertainty in a source-receptor transfer matrix covering all Europe. In the last part of the paper we use this method to investigate the reliability of different emission scenarios in reducing deposition.

\section{ANALYZING INDIVIDUAL UNCERTAINTIES}

\subsection{Method}

In the first part of our analysis, we focus on the source-receptor combinations noted in Table 1. These were selected because they provide a good range of geographic and meteorological conditions and can be compared with earlier studies of the authors.

In Alcamo and Bartnicki (1987) we presented a taxonomy of uncertainties of the EMEP I model to assist in organizing sources of uncertainty. Because of the similarity of the models, we believe this taxonomy applies as well to the EMEP II model. Using this taxonomy as a guide we now briefly review our considerations for omitting certain sources of uncertainty.

Errors that relate to model structure are among the most difficult to analyze because for every model there is a large number of reasonable alternative formulations of model equations. The authors examined the effect of adding a non-linear wet deposition formulation to the EMEP I model, as an example of a model structure investigation, but in this paper we will not deal with this subject.
Table 1. Source countries and receptors used for uncertainty analysis

\begin{tabular}{ll}
\hline Source country & \multicolumn{1}{c}{ Receptor } \\
\hline G.D.R. & Illmitz, Austria \\
U.K. & Rorvik, Sweden \\
The Netherlands & Tange, Denmark \\
\hline
\end{tabular}

Initial state errors relate to initial condition and boundary conditions. We tested the effect of initial conditions by computing annual average $\mathrm{SO}_{2}$ air concentration and annual wet and dry $\mathrm{S}$ deposition at Illmitz, Austria, (only accounting for emissions from the G.D.R.) with and without initial conditions at the beginning of each $96 \mathrm{~h}$ trajectory. The effect of including initial conditions was to increase $\mathrm{SO}_{2}$ and $\mathrm{S}$ deposition by $0.2 \%$ and $0.4 \%$, respectively. We conclude that the uncertainty of initial conditions is not significant in the EMEP II model when applied to sulfur transport in central Europe. Other examples of 'initial state' uncertainty are the boundary conditions of the model. These include horizontal boundary conditions - concentrations of sulfur in trajectories at the edge of the model study area; and vertical boundary conditions-flux of S from the free troposphere into the assumed mixing layer. (See the model equations in Appendix A for a more detailed explanation of these boundaries.) A study of these uncertainties is outside the scope of this paper even though they may be an important source of model uncertainty in areas remote from major sources.

One type of forcing function uncertainty which receives attention in the literature (e.g. Streets et al., 1985; Niemann, 1988) is the effect of interannual meteorological variability. In studying the EMEP I model, Alcamo and Posch (1986) found that this variability caused a $13 \%$ average relative deviation in computed $\mathrm{S}$ deposition (when all emission sources were taken into account). This was found to be roughly the same or smaller in magnitude than other uncertainties (Alcamo, 1988). Since the EMEP II model has a better treatment of meteorological inputs, we expect this uncertainty to be still smaller. In this paper we will focus on uncertainties for a particular meteorological year and therefore will not deal with interannual meteorological variability. However, this subject should be addressed in future studies.

'Model operation' errors in the EMEP II can arise from the solution of model equations, and other sources. From model experiments, the authors have found that numerically solving the EMEP II equations creates only a small amount of artificial dispersion because of the linearity of the equations. These and other sources of model operation errors are not considered important sources of error in the EMEP II model.

After the preceding considerations, we are still left with the large list of uncertainties we deal with in this 
paper: transport wind, meteorological forcing functions (mixing height, wind speed, and so on), parameters and emissions. We now describe our method for analyzing each of these uncertainties.

Transport wind uncertainty. One of the critical assumptions in computing the trajectory of an air pollution in a single vertical layer model (such as EMEP II) is the assumed elevation of the mean transport wind, i.e. the representative level at which pollutants are transported away from pollutant sources. In the EMEP II model, this is assumed to be $850 \mathrm{hPa}$ which is at approximately $1500 \mathrm{~m}$ - close to the maximum mixing height rather than the average transport level. (A new version of this model will use $925 \mathrm{hPa}$.) We estimate the effect of this very uncertain estimate by dividing the boundary layer into 10 equal vertical levels from the $850 \mathrm{hPa}$ level to the $50 \mathrm{~m}$ surface layer. We term these different levels 'wind classes'. For each of these ten wind classes we recompute a new set of annual trajectories, and then compute a new deposition at each receptor. We compute the uncertainty of deposition by assigning a probability of occurrence to each of these wind classes. This probability is expressed in the form of a frequency distribution which is presented and explained in Appendix B.

Meteorological forcing functions. To assess the uncertainty caused by uncertain meteorological forcing functions (other than transport wind) we use a stochastic simulation method. We first assign frequency distributions to each of these meteorological inputs which reflect their uncertainty. These distributions are based on information about their measurement error, and are presented in Appendix B. We select a new set of values from these distributions every $6-12 \mathrm{~h}$ along each trajectory (precipitation, surface wind, $850 \mathrm{hPa}$ wind, every $6 \mathrm{~h}$; mixing height, every $12 \mathrm{~h}$ ). After selecting these inputs for every trajectory, we solve model equations and compute annual sulfur deposition and concentration at different receptors. This procedure is repeated for several annual runs and the variance of annual model output is then computed.

Parameter uncertainties. Our approach to parameter uncertainty is similar to that used to assess uncertainty due to meteorological forcing functions. Each parameter is assigned a frequency distribution, and stochastic simulation is used to produce output uncertainties. The assigned input frequency distributions are presented in Appendix B. In comparison to the forcing functions, which are sampled every 6$12 \mathrm{~h}$, new parameter values are selected only at the beginning of each 1-year simulation. This is consistent with the usage of parameters in the model. In Alcamo and Bartnicki (1987), the authors used simple Monte Carlo sampling to select parameter values, but this required from 400 to 1500 computer runs. In the current study, however, we limited the required number of runs to 20 based on the Latin Hypercube Sampling method (McKay et al., 1979; Derwent and Hov, 1987).

Emissions uncertainty. The uncertainty due to emis- sions can be divided into two parts-(1) uncertain country emissions, and (2) uncertain spatial distribution of emissions in a grid within each country. Since deposition is linearly related to emissions in the EMEP II model, we know, for example, that a $30 \%$ error in country emissions will result in a $30 \%$ error in deposition at a receptor only affected by these emissions. Consequently, further evaluation of (1) is not required and we will focus on (2) which has a less obvious effect on model uncertainty. To investigate the effect of uncertain spatial distribution of emissions we compiled three different grid emission inventories (Amble, 1981; Dovland and Saltbones, 1978, 1986). These are assumed to represent the variation of grid emissions estimates owing to different assumptions about population, location of emission sources, and so on. To compute output uncertainty, we simply compute $\mathrm{S}$ deposition at each receptor due to each of the three emission inventories while keeping country totals constant. We then compute the variance of these depositions by assuming that these outcomes have an equal probability.

Alcamo (1988) presented an analytical solution for computing uncertainty due to the uncertainty of spatial distribution of emissions which requires only an estimate of transfer coefficients and the error of emissions. Although this analytical solution is simpler than the stochastic method described above, we will use the stochastic method in this paper because it allows us to link emission uncertainties with other types of uncertainties, as we describe later in this paper.

\subsection{Comparison of results for individual uncertainties}

Figure 1 shows the relative* uncertainty of computed total (wet + dry) sulfur deposition as it is affected by different types of uncertainty. The effect of parameter uncertainty is about the same for all receptors, resulting in an uncertainty of $6.6-8.2 \%$ in computed total sulfur deposition. This was a much smaller effect on deposition than parameters had in an earlier study of the EMEP I model (Alcamo and Bartnicki, 1987). This is despite the fact that input parameter uncertainties were of roughly the same magnitude (in this study, input parameter c.v. $=10-40 \%$, in the earlier study c.v. $=20 \%$ ). One possibility is that the better defined, and less aggregated, description of atmospheric processes in the EMEP II model reduces its output uncertainty. Also, accounting for covariance between parameters may increase or decrease deposition uncertainty (Alcamo and Bartnicki, 1987). Meteorological forcing functions as defined above had a small effect on all receptors (c.v. of $1.8-2.4 \%$ ). This is because these inputs are prescribed at relatively

* In this paper we refer to absolute and relative uncertainty. Absolute uncertainty is the standard deviation $(\sigma)$. Relative uncertainty is the coefficient of variation in $\%$, i.e.

$$
\text { c.v. }=\frac{\sigma}{\bar{x}} \times 100 \% \text {. }
$$


short intervals (every 6 or $12 \mathrm{~h}$ ); their errors average out over a 1-year simulation period. The effect of uncertain spatial distribution of emissions on output uncertainty ranged from minor $(1.0 \%)$ to moderate $(5.1 \%)$. The spatial distribution of emissions were also found to have much smaller effect on computed S deposition than in an earlier study of the EMEP I model (Alcamo, 1987). However, the previous study did not account for covariance between grid emissions, which may explain the larger error estimates. The effect of wind had by far the largest variability between receptors, ranging from 2.5 to $19.1 \%$. This is because of the complicated, non-linear interaction of various factors: (1) the size of the source country, (2) the distance between source and receptor, and (3) the number of trajectories arriving at a receptor from the source country.

In general, Fig. 1 points out that by improving individual model inputs such as parameters, forcing functions, and so on, we would not uniformly reduce the error of deposition calculations at all European locations.

\section{COMPOSITE UNCERTAINTY ANALYSIS}

\subsection{Method}

After reviewing the effect of separate types of uncertainty for different source-receptor combinations, we now look at the combined effect of these different uncertainties on the same source-receptor combinations. Our algorithm for doing so is outlined in Fig. 2. At the beginning of each 1-year model run we select a 'wind class', as explained above, to represent the mean transport wind. We also choose a set of parameters, and one out of the three possible emission inventories. At each 6-h or 12-h computational interval along each trajectory, we select a set of meteorological forcing functions as described above. We repeat the entire procedure 60 times, i.e. 601 -year runs are performed. This is in order to obtain a statistically significant sample of the input distributions of wind uncertainty. We derive ' 60 ' from the following 'stratified sampling' considerations: the input distribution of wind uncertainty is divided into 10 classes (Appendix B) and at least one run must be performed for the class with the lowest probability; the number of runs for other classes is proportional to their probabilities. Following these guidelines, the required number of runs for the wind uncertainty analysis is 60 . We explained previously that only 20 computer runs are required for parameter uncertainty, and three for emissions. (Other meteorological forcing functions are sampled at 6- or 12-h intervals within an annual period and thus are not relevant to this discussion.) Therefore, to obtain a statistically significant sample of all inputs (wind, parameters, emissions) we must repeat our model experiments for the limiting number of times -60 .

In our analysis we did not account for covariance between input parameters, forcing functions or other inputs because it was outside the scope of the current study. However, as noted above, covariance between inputs could affect the results of the uncertainty analysis.

\subsection{Results of composite uncertainty on selected source-receptor combinations}

Effect on total deposition. The composite effect of uncertain parameters, transport wind, spatial distribution of emissions and meteorological forcing functions on computed total (wet plus dry) sulfur deposition is presented as the top bars in Figs 1(a)-(c). Note that the computed composite uncertainty is always smaller than the sum of the individual uncertainties, which is to be expected since covariance between input distributions was not taken into account. Composite uncertainty of total deposition (relative uncertainty) ranges from 10.4 to $19.6 \%$ for the three receptors. In Fig. 3 we present their frequency distributions. (These distributions were computed with 200 rather than 60 runs because 60 runs were sufficient to accurately estimate the first two moments of the distribution but not its shape.)

To appreciate the magnitude of this uncertainty-a computed total sulfur deposition of $1.0 \mathrm{~g} \mathrm{~m}^{-2} \mathrm{yr}^{-1}$ would have a $95 \%$ confidence interval of about $0.7-1.3 \mathrm{~g} \mathrm{~m}^{-2} \mathrm{yr}^{-1}$ (assuming normality).

Effect on other model output. In Fig. 4 we compare the composite uncertainty of a number of different model outputs. Again there is no distinct pattern between receptors. Dry deposition has the largest uncertainty at Illmitz, Austria, sulfate air concentration at Rorvik, Sweden, and wet deposition at Tange, Denmark. The uncertainty of total deposition, however, is always lower than the average of wet and dry deposition, indicating a compensation in errors between these two components.

\section{ROUTINE CALCULATIONS - COMPOSITE UNCERTAINTY OF MULTIPLE SOURCES}

\subsection{Method}

To this point we have examined the effect of different types of uncertainty (parameter, wind, etc.) on computed concentration and deposition for three different source-receptor combinations. We then looked at the composite effect of several sources of uncertainty on the same source-receptor combinations ('composite uncertainty'). We now continue our analysis of composite uncertainty, but rather than focusing on single source-receptor combinations, we add up the effect of all important source countries on particular receptors. In other words, we now concentrate on the practical problem of estimating the un: certainty of sulfur deposition computed with a source-receptor transfer matrix. Our ultimate objective is to find a method to routinely calculate this uncertainty. 
(a) GDR-IIImitz

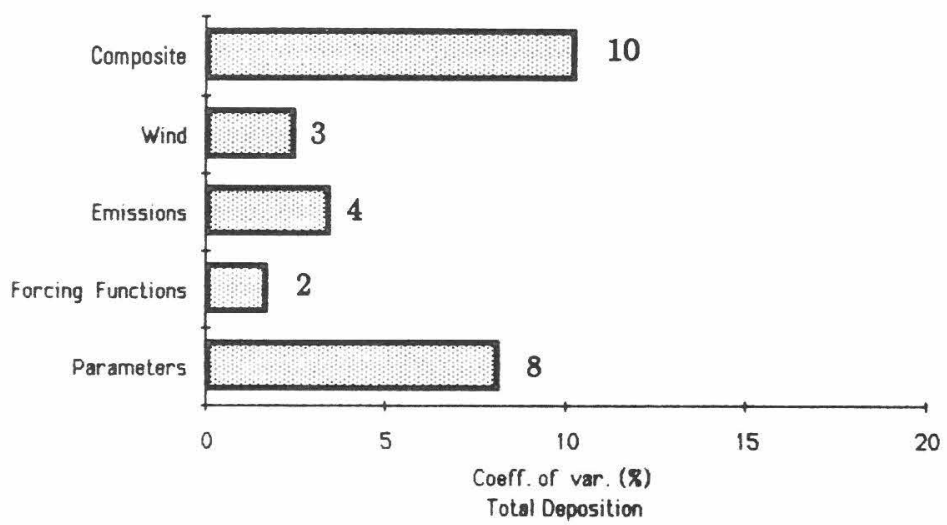

(b) UK-Rorvik

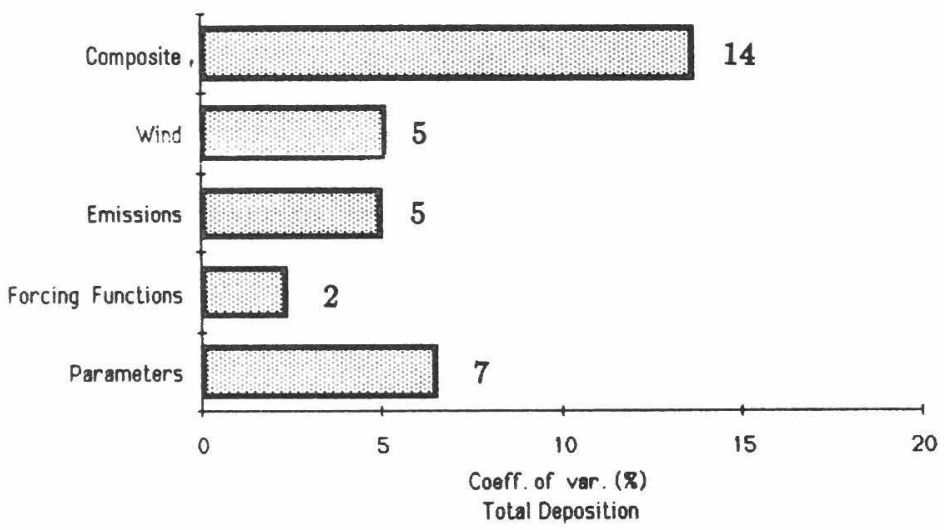

(c) The Notheriands-Tange

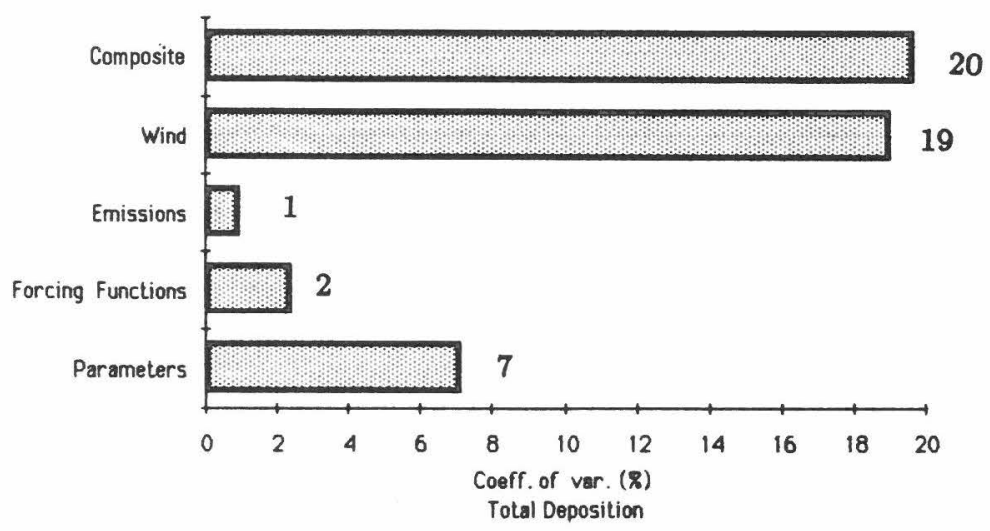

Fig. 1. Relative uncertainty of computed total sulfur deposition due to different input uncertainties, (a) Illmitz, Austria, due to emissions from the German Democratic Republic, (b) at Rorvik, Sweden, due to emissions from the U.K., (c) at Tange, Denmark, due to emissions from The Netherlands. 


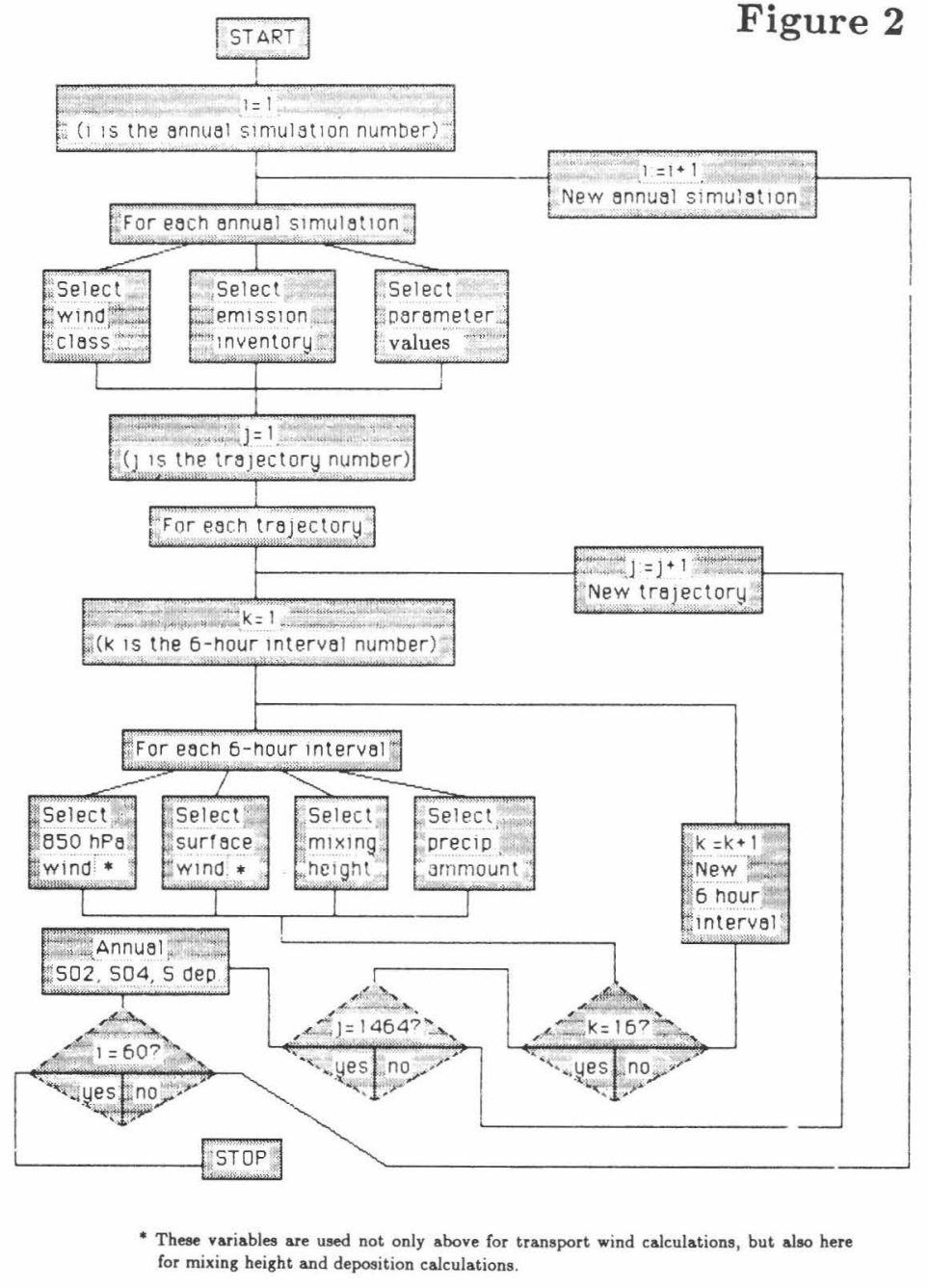

Figure 2

Fig. 2. Algorithm for composite uncertainty analysis.

In using a transfer matrix, deposition at any location $j$, is computed by

$$
d_{j}=\sum_{i=1}^{N} S_{i} a_{i j}+b_{j}
$$

where $d_{j}$ is the total (wet plus dry) sulfur deposition, $S_{i}$ is the emissions of country $i, a_{i j}$ is the transfer coefficient of deposition at receptor $j$ per unit emissions from country $i$, and $b_{j}$ is the background deposition at receptor $j$.

Since Equation (1) is a linear combination of $S_{i}$ and $a_{i j}$, the variance of the deposition can be simply calculated from the Gaussian error equation as:

$$
\sigma_{d_{j}}^{2}=\sum_{i=1}^{N} S_{i}^{2} \sigma_{a_{i j}}^{2}+2 \sum_{\substack{m, n=1 \\ m \neq n}}^{N} S_{m} S_{n} \operatorname{cov}\left(a_{m j}, a_{n j}\right) .
$$

In this equation we neglect the uncertainty of background deposition, $b_{j}$, because it is outside the scope of this paper. The authors point out, however, that background uncertainty can be quite important in locations distant from dense industrial areas, as in Scandinavia.

In practice, Equation (1) is used to analyze control strategies, i.e. to compute a new deposition at any or all grid locations $j$, as individual country emissions increase or decrease (e.g. Shaw, 1986; Hordijk, 1986). We propose that Equation (2) can be used at the same time to compute the error $\sigma_{d_{j}}^{2}$ of this deposition estimate. Note in Equation (2) that this error depends only on the emissions from each country, $\left(S_{i}\right)$, the variance of the transfer coefficients $\left(\sigma_{a_{i j}}^{2}\right)$ and the covariance between transfer coefficients $\left[\operatorname{cov}\left(a_{m j}, a_{n j}\right)\right]$. Since the emissions from different countries are externally input to the deposition calculation, we are left with finding the variance and covariance of the transfer coefficients. Consequently we devote the remainder of this paper to this estimation of these statistics with the aim to use Equation (2) for routine calculations of deposition uncertainty. We concentrate on deposition rather than air concentration, because of deposition's greater importance in 
(a) IIImitz

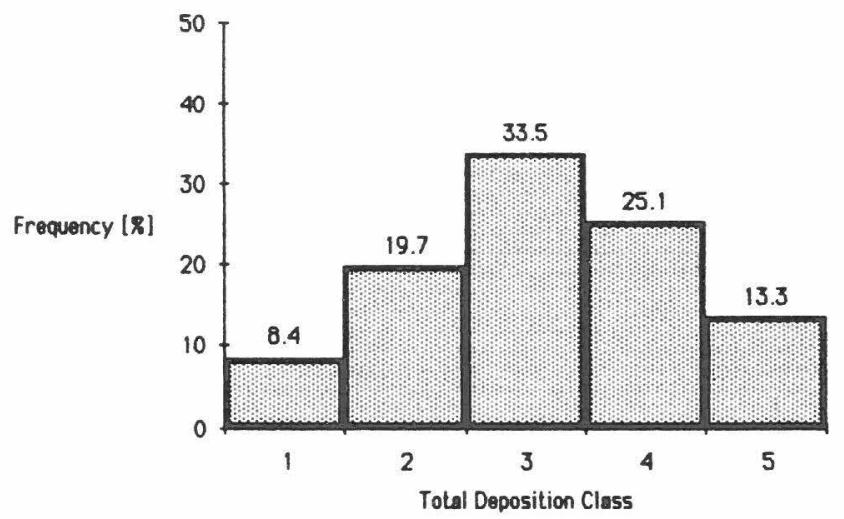

(b) Rorvik

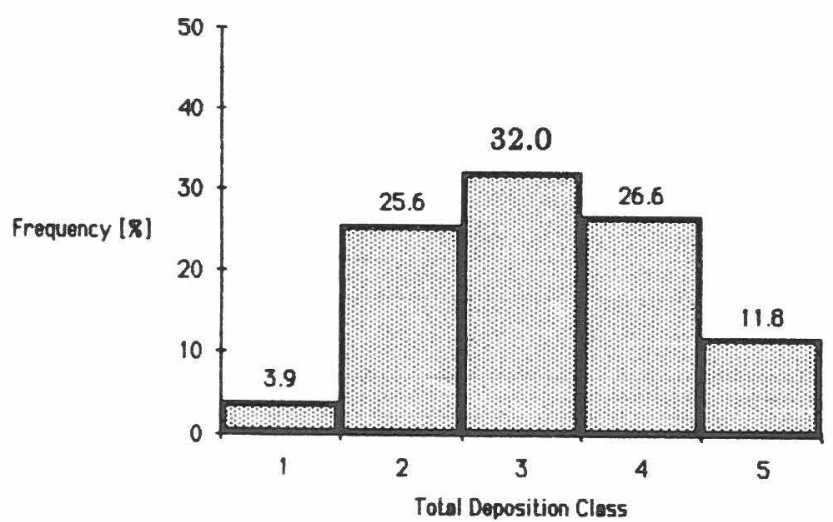

(c) Tenge

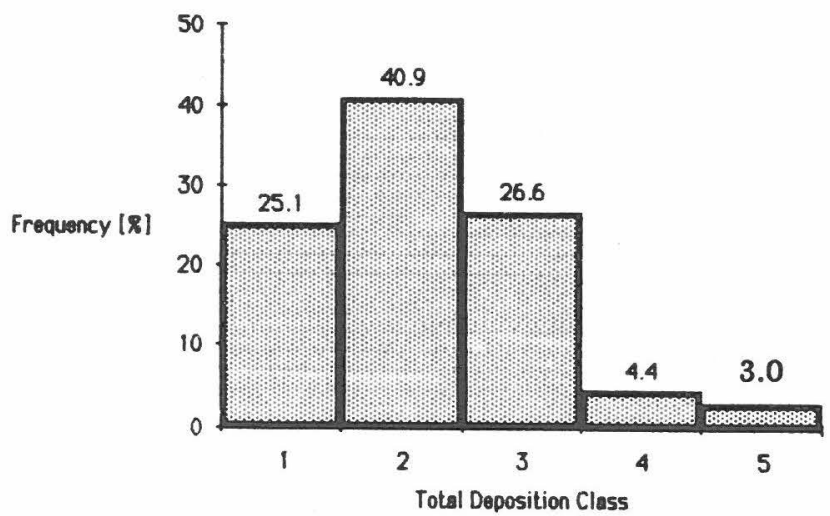

Fig. 3. Computed frequency distributions of total sulfur deposition, (a) Illmitz, Austria, due to emissions from the G.D.R., (b) at Rorvik, Sweden, due to emissions from the U.K., (c) at Tange, Denmark, due to emissions from The Netherlands. 
(a) -11imitz

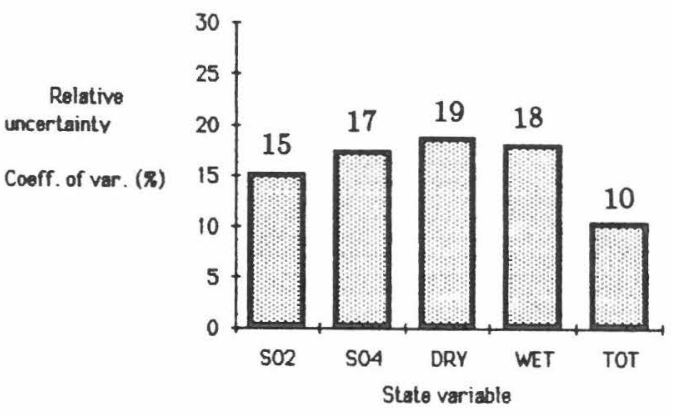

(b) -Rorvik

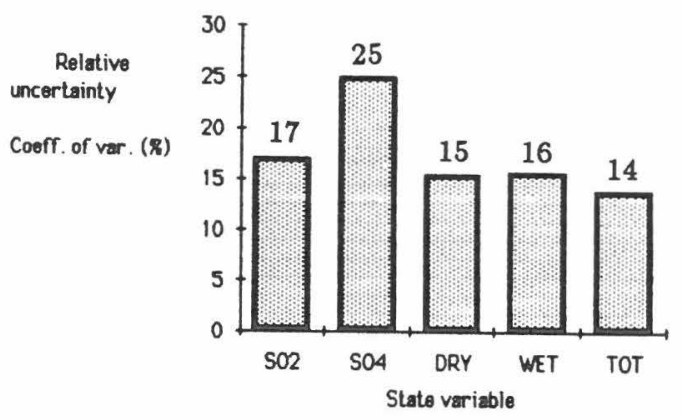

(c) -Tange

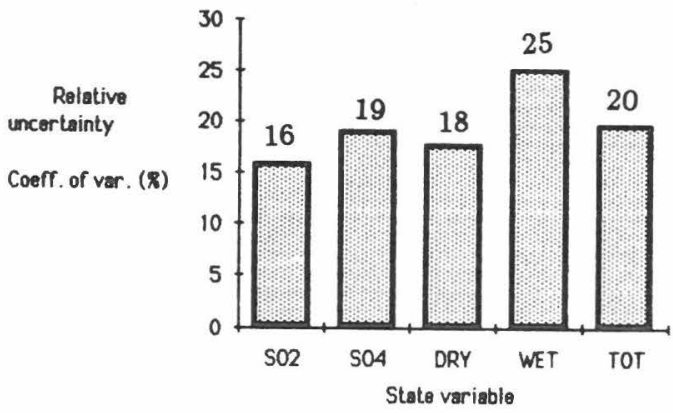

Fig. 4. Composite uncertainty of model state variables (a) Illmitz, Austria, due to emissions from the G.D.R., (b) at Rorvik, Sweden, due to emissions from the U.K., (c) at Tange, Denmark, due to emissions from The Nether-

$$
\text { lands. }
$$

the evaluation of international sulfur control strategies. Our approach will be to first compute the uncertainty of several transfer coefficients from model experiments, and then to use these as a 'raw data' to derive a general formula for calculating the uncertainty of all coefficients in the transfer matrix. Of course we could simply compute the uncertainty of each transfer coefficient using the method in section 3 , but this would be a daunting computational task requiring 60 annual computer runs for each of about 19,000 transfer coefficients.
Estimating uncertainty of transfer coefficients. In section 3.1 above we described a method to compute the composite uncertainty of deposition. This method can also be used to compute the uncertainty of transfer coefficients because the relative uncertainty of deposition is equal to the relative uncertainty of transfer coefficients.* Also, absolute uncertainty of transfer coefficients is simply $\sigma_{a_{i j}}=\sigma_{d_{i j}} / S_{i}$. We now proceed to calculate the uncertainty of transfer coefficients between three receptors and 10 countries that contribute the most deposition to each receptor. $\dagger$ As a result we obtain a total of 30 estimates for $\sigma_{a_{i j}}$ and c.v. $a_{a_{i j}}$. These are 'raw data' for our analysis. We now try to identify a relationship between the uncertainty of these transfer coefficients and a distance parameter (representing distance between source countries and receptor grid elements). Such a relationship would allow us to generalize results from 30 transfer coefficients to all transfer coefficients in the transfer matrix once we know the distance between sources and receptors.

\subsection{Results}

Relative uncertainty vs distance. We begin by examining the relative uncertainty of the transfer coefficient vs (1) geographic distance (emission-weighted) and (2) number of trajectories arriving at a receptor (Figs 5a and $b$ ). We use the number of trajectories arriving at a receptor as a surrogate of distance because it takes into account both geographic distance as well as whether a source is upwind or downwind of a receptor, i.e. we expect that the closer and more upwind a source is to a receptor, the larger the number of trajectories arriving at a receptor from that source. These figures show that relative uncertainty is not related to distance. On the one hand we expect uncertainty to increase with distance downwind from a source as errors (e.g. in parameters and wind trajectories) accumulate in the long range transport calculations. On the other hand we might also expect uncertainty to increase close to sources because the model is not designed to simulate short-range transport, i.e. its key assumptions (single vertical layer, complete mixing, isobaric transport) do not hold well for short travel distances. Because of this, uncertain spatial distribution of emissions and the uncertain local deposition

$$
\begin{aligned}
& \text { *Since } \\
& \text { and } \\
& \qquad d_{i j}=S_{i} a_{i j} \\
& \qquad \sigma_{d_{i j}}=S_{i} \sigma_{i j} \\
& \text { then } \\
& \qquad \text { c. } \cdot d_{d_{i j}}=\frac{\sigma_{d_{i j}}}{d_{i j}}=\frac{S_{i} \sigma_{a_{i j}}}{S_{i} a_{i j}}=\frac{\sigma_{a_{i j}}}{a_{i j}}=\text { c.v } \cdot_{a_{i j}} . \\
& \text { † These } 10 \text { countries are determined by the RAINS model } \\
& \text { (Alcamo } \text { et al., 1987) based on a 4-year average EMEP matrix } \\
& \text { from } 1978,1979,1982,1983 \text {. Ten countries are usually } \\
& \text { sufficient for accounting for over } 90 \% \text { of the deposition to } \\
& \text { each receptor (not including background). }
\end{aligned}
$$


(s)

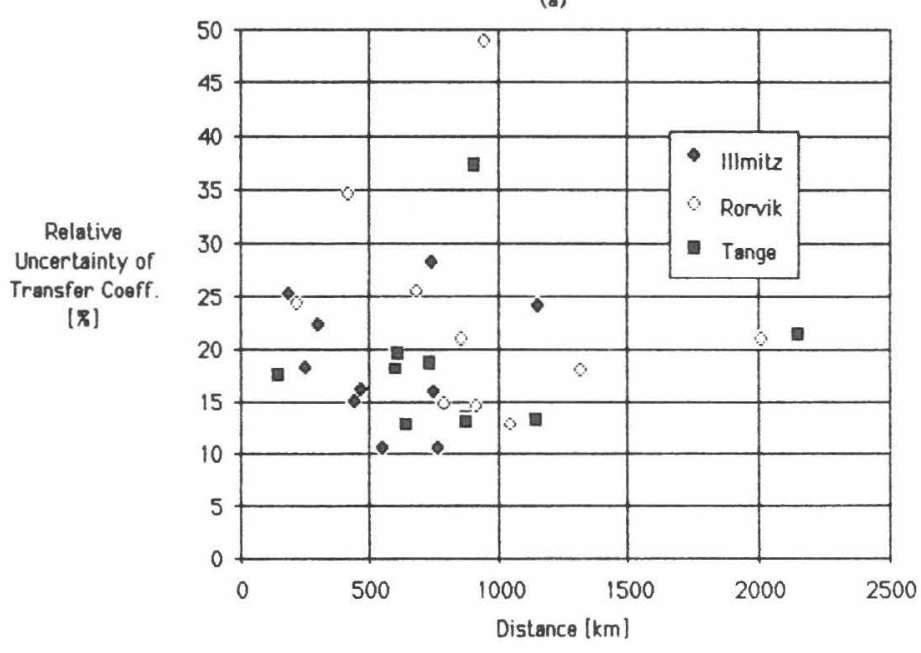

(b)

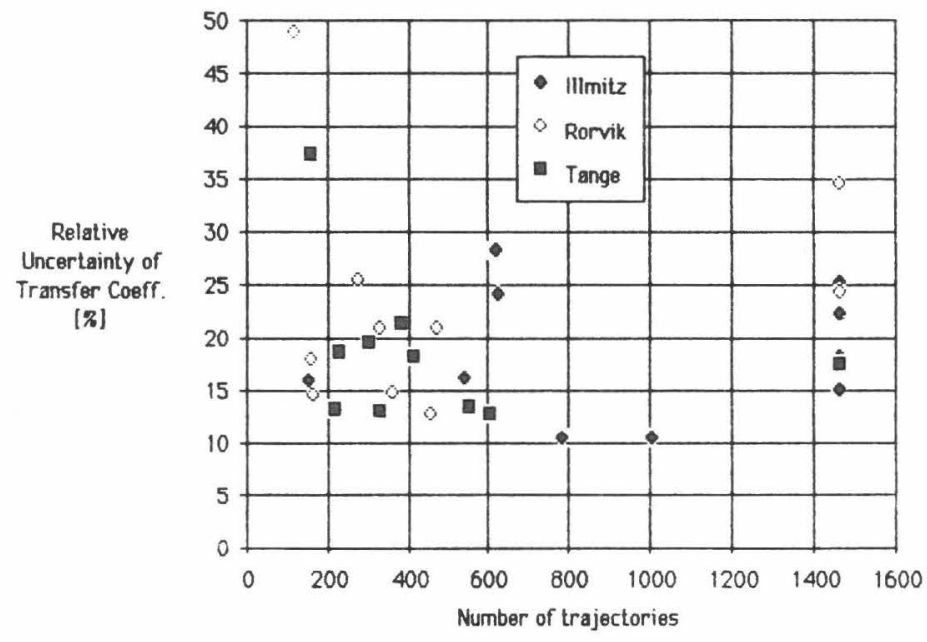

Fig. 5. Relative uncertainty of transfer coefficients: (a) vs distance between sources and receptors, (b) vs number of trajectories arriving at receptors from source countries.

coefficient (see Appendix B) can cause a large uncertainty in computed deposition close to sources. One interpretation of Figs $5 a$ and $b$ is that we see a combination of these effects, and the model performs roughly the same between 100 and $2000 \mathrm{~km}$, with a relative uncertainty between 10 and $30 \%$.

A plot of absolute uncertainty vs distance of sources to receptors (Fig. 6a) shows a clear exponential decrease of this uncertainty. A log-log plot (Fig. 6b) magnifies the distribution of low values in the arithmetic plot of Fig. 6a. A linear regression of $\log \sigma_{a_{i j}}$ vs $\log$ distance shows a significant correlation $\left(r^{2}=0.82\right)$ with the best fit:

$$
\log \sigma_{a_{i j}}=1.8147-2.3678 \log x_{i j}
$$

where $x_{i j}$ is the emission-weighted distance between the source country and receptor.
Equation (3) can be used to generate the $\sigma_{a_{i j}}$ matrix needed for Equation (2) once the distance from each source to each receptor is known. Although we can use Equation (3) to calculate $\sigma_{a_{i, j}}^{2}$ in Equation (2), the exponential decrease of $\sigma_{a_{i j}}$ with distance suggests that $\sigma_{a_{i j}}$ may be related to the transfer coefficients themselves. If this is true, then the uncertainty calculations in Equation (2) can be greatly simplified, as will be shown shortly. Figure $7 \mathrm{a}$ shows that transfer coefficients decrease the same way with distance as absolute uncertainty. The log-log plot of $a_{i j}$ vs distance (Fig. $7 \mathrm{~b}$ ) is as convincing as the log-log plot of absolute uncertainty vs distance (Fig. 6b). Here we have a clear expression of the intuition that unit deposition contributions from countries to receptors drop off more or less consistently with distance. The regularity of this drop-off is surprising, however, because we expected a 
(a)

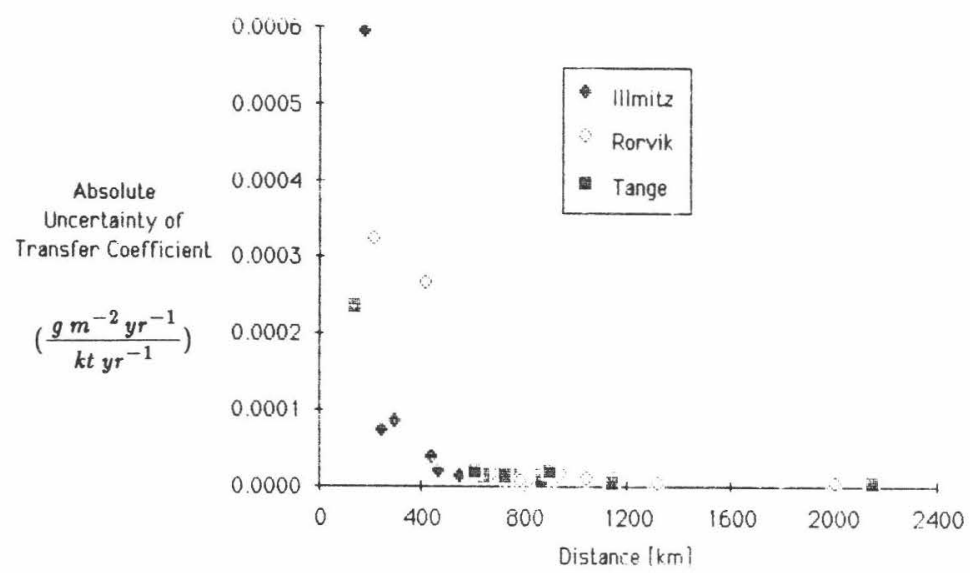

(b)

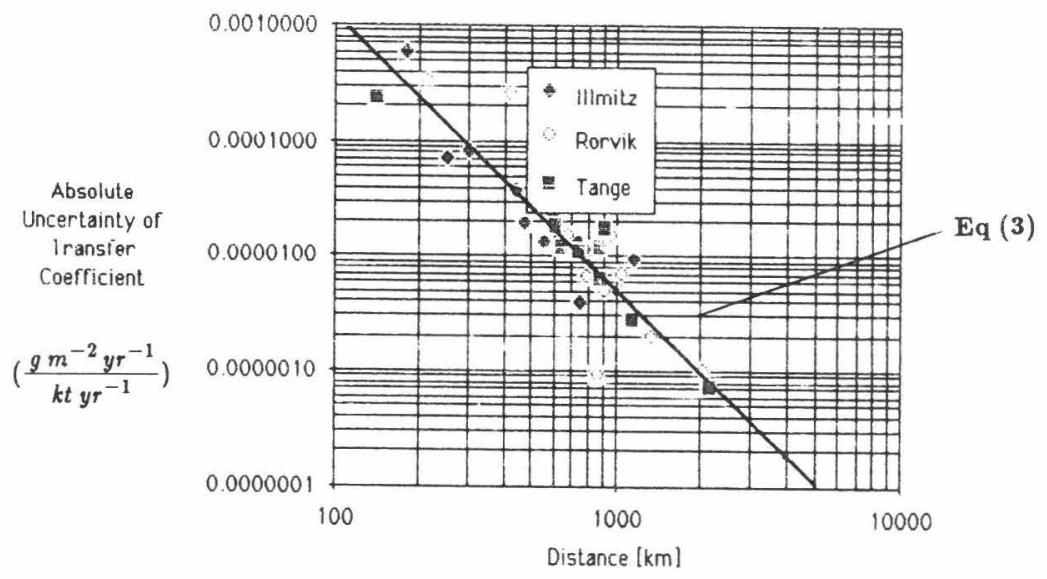

Fig. 6. Absolute uncertainty of transfer coefficients vs distance between sources and receptors: (a) arithmetic plot, (b) logarithmic plot.

country's contribution to a receptor also to be a function of whether the country is, on the average, upwind or downwind from the receptor. But as Fig. 5b showed, there was no relation between relative uncertainty and number of trajectories arriving at a receptor from a country.

With both $a_{i j}$ and its absolute uncertainty correlating to distance, the obvious next step is to examine $\sigma_{a_{i j}}$.vs $a_{i j}$. A log-log plot depicts more clearly the smaller values of these variables (Fig. 8) and confirms their close relationship. To determine the best-fit line, we conducted a two-stage least square analysis of $\sigma_{a_{i j}}$ vs $a_{i j}$ (note, arithmetic not logarithmic), and used distance as an instrumental variable. This type of analysis accounts for the correlation of both $\sigma_{a_{i j}}$ and $a_{i j}$ to distance. The computed regression line had an $r^{2}$ of 0.96. (To ensure that this significant correlation did not only depend on the four largest points in Fig. 8, the analysis was repeated after eliminating these points. An $r^{2}$ of 0.92 was still computed.)
By forcing the constant in the regression equation to zero we obtain

$$
\sigma_{a_{i j}}=0.227 a_{i j} .
$$

The fit of this regression is similarly good $\left(r^{2}=0.95\right)$ and it has the advantage that the factor 0.227 can be thought of as a 'characteristic' coefficient of variation of $a_{i j}$. (We note that the factor 0.227 is close to the average of the 30 points in Fig. $7 \mathrm{c} \overline{c v}_{a_{i j}}=0.201$ ). The $\sigma_{a_{i j}}$ can now be easily computed from the matrix of transfer coefficients and we do not need to compute and store a large $\sigma_{a_{i j}}$ matrix by Equation (3).

Covariance between transfer coefficients. Although the relationship in Equation (4) provides an easy way to compute $\sigma_{a_{i j}}^{2}$ in Equation (2), we must still decide how to deal with the covariance terms, i.e. we must now address the effect of covariance between transfer coefficients. This is far from a trivial problem since there are about $10^{5}$ potential covariances in a transfer matrix with about 700 receptors and 27 countries. 
(a)

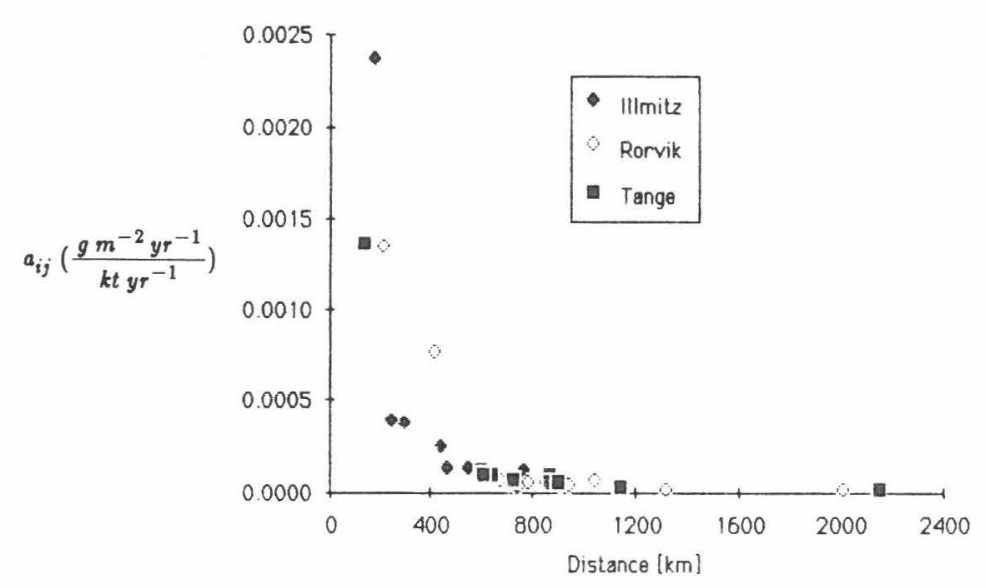

(b)

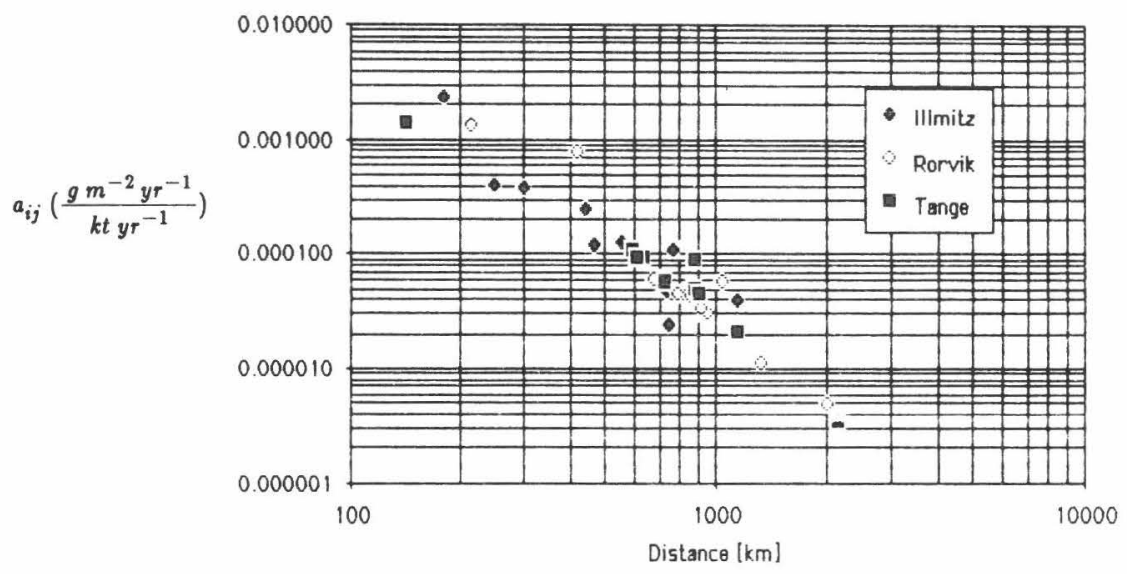

Fig. 7. Transfer coefficients vs distance between sources and receptors: (a) arithmetic plot, (b) logarithmic plot.

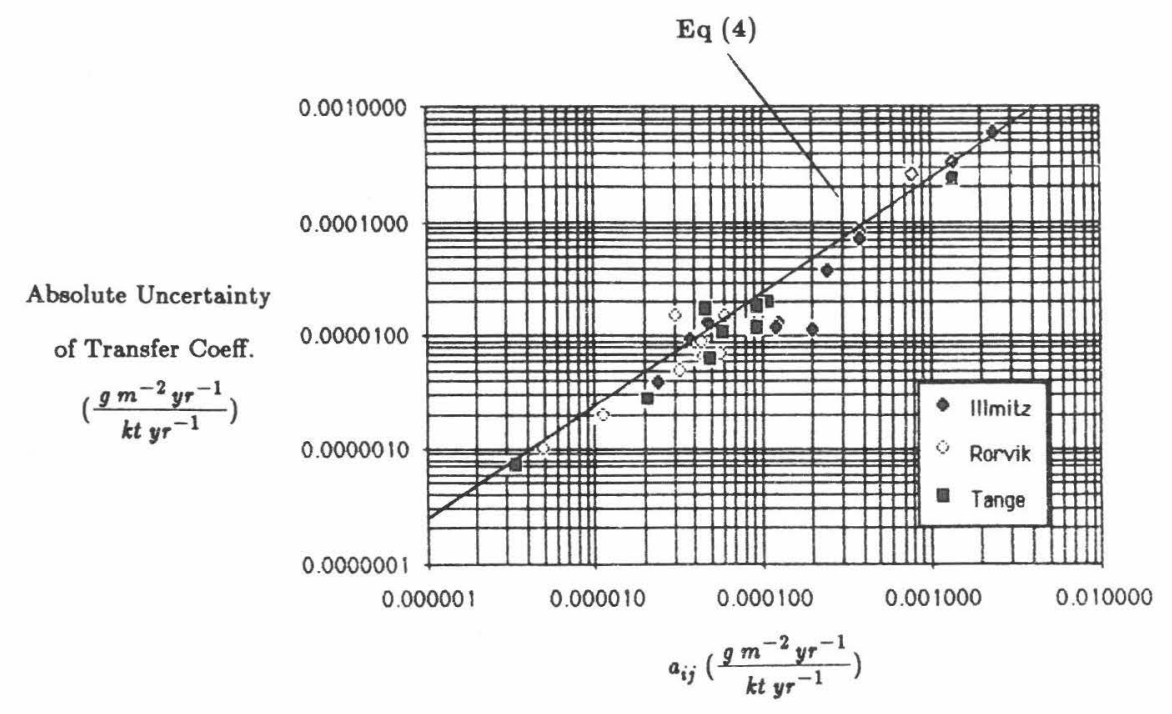

Fig. 8. Absolute uncertainty of transfer coefficients vs transfer coefficients. 
Table 2. Correlation between transfer coefficients to Illmitz. (a) Variance-covariance matrix, (b) correlation coefficients

\begin{tabular}{|c|c|c|c|c|c|c|c|c|c|c|}
\hline & CZE & AUS & HUN & GDR & $P O L$ & $Y U G$ & ITA & FRG & $F R A$ & $R O M$ \\
\hline \multicolumn{11}{|c|}{ (a) Verience-covarience metris } \\
\hline CZE & $0.6890-08$ & & & & & & & & & \\
\hline AUS & $0.1140-07$ & $0.3540-06$ & & & & & & & & \\
\hline HUN & $0.305 e-08$ & $0.2580-07$ & $0.4920-08$ & & & & & & & \\
\hline GDR & $0.389 e-09$ & $-0.4670-08$ & $-0.236 e-09$ & $0.1670-09$ & & & & & & \\
\hline POL & $0.685 \mathrm{e}-09$ & $-0.6860-09$ & $-0.7830-09$ & $0.150 e-10$ & $0.3680-09$ & & & & & \\
\hline YUG & $-0.1110-08$ & $-0.1190-07$ & $-0.1940-09$ & $-0.248 e-09$ & $0.5980-10$ & $0.1370-08$ & & & & \\
\hline ITA & $-0.4010-09$ & $-0.5190-08$ & $-0.7860-09$ & $-0.988-10$ & $-0.146 e-09$ & $-0.8110-10$ & $0.1730-09$ & & & \\
\hline PRG & $0.4970-09$ & $-0.1130-08$ & $0.2910-09$ & $0.7310-10$ & $0.1450-09$ & $-0.1540-09$ & $-0.3260-10$ & $0.1286-09$ & & \\
\hline FRA & $-0.3820-09$ & $-0.3810-08$ & $-0.5370-09$ & $0.5780-10$ & $-0.806 e-10$ & $-0.1870-10$ & $-0.1100-09$ & $-0.1160-10$ & $0.8270-10$ & \\
\hline ROM & $-0.625-10$ & $-0.1540-08$ & $-0.8500-10$ & $0.2840-10$ & $-0.3940-11$ & $-0.2330-10$ & $0.2950-10$ & $-0.9500-12$ & $0.2100-10$ & $0.1440-10$ \\
\hline \multicolumn{11}{|c|}{ (b) Correlation coefficient } \\
\hline CZE & 1.00 & & & & & & & & & \\
\hline AUS & 0.23 & 1.00 & & & & & & & & \\
\hline HUN & 0.52 & 0.62 & 1.00 & & & & & & & \\
\hline GDR & 0.36 & -0.61 & -0.28 & 1.00 & & & & & & \\
\hline POL & 0.43 & 0.06 & 0.58 & 0.06 & 1.00 & & & & & \\
\hline YUG & -0.36 & 0.54 & 0.07 & -0.52 & 0.08 & 1.00 & & & & \\
\hline ITA & -0.37 & -0.66 & -0.85 & 0.58 & -0.58 & -0.17 & 1.00 & & & \\
\hline FRG & 0.53 & -0.17 & 0.37 & 0.50 & 0.67 & -0.37 & -0.22 & 1.00 & & \\
\hline FRA & -0.51 & -0.70 & -0.84 & 0.49 & -0.46 & -0.08 & 0.09 & -0.11 & 1.00 & \\
\hline ROM & -0.20 & -0.68 & -0.32 & 0.58 & -0.05 & -0.17 & 0.59 & -0.02 & 0.61 & 1.00 \\
\hline
\end{tabular}

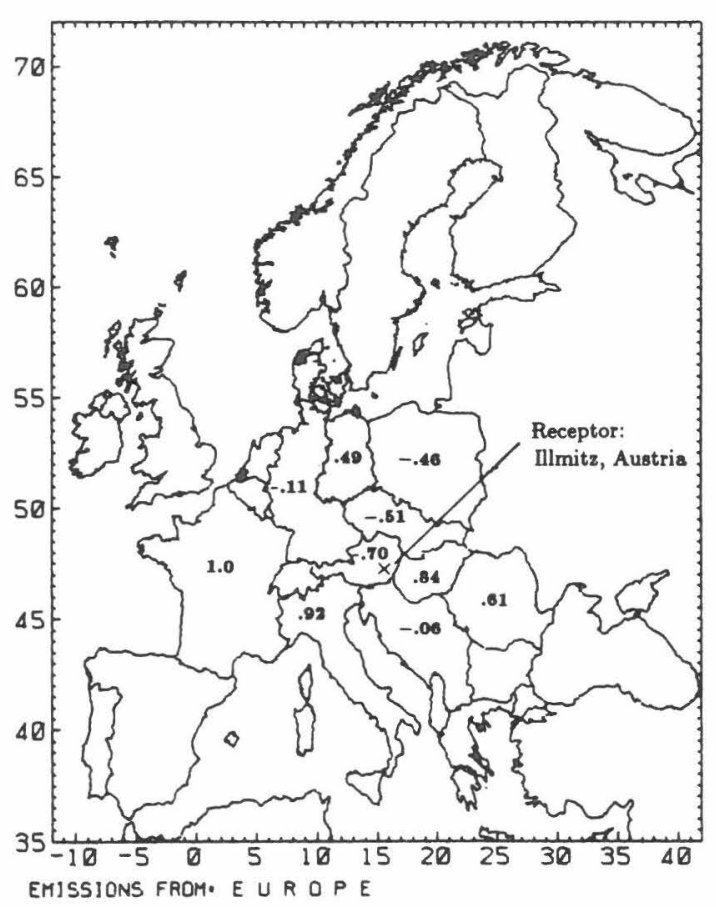

Fig. 9. Correlation $(\rho)$ between transfer coefficient of France and other countries. Receptor: Illmitz, Austria.

We begin by examining the variance-covariance matrix for one of the receptors (Illmitz) (Table $2 \mathrm{a})^{*}$. This table was derived from results of the composite uncertainty analysis described in section 3 . Note that the covariance of transfer coefficients between two different countries may be either negative or positive, which suggests that they may compensate if we sum the contributions of several countries together. The corresponding correlation coefficients between coun-

* This is actually only a part of the total var-cov matrix because transfer coefficients going to different receptors can also co-vary with one another. tries contributing to Illmitz are also rather low (Table 2b). Exceptions are the relationships between Italy-Hungary and France-Hungary $(\rho=-0.85$ and -0.84 , respectively) and France-Italy $(\rho=0.92)$. Similar results are found for the receptors Rorvik and Tange. No simple relation for covariance can be seen in these tables. In Fig. 9 we try a visual plot of covariance, and depict the correlation coefficient of France to nine other countries that contribute to deposition at Illmitz. On one hand there is the expected close correlation between France and adjacent Italy $(\rho=0.92)$; but between France and another adjacent country, F.R.G., there is virtually no correlation $(\rho=0.11)$. We might expect a negative correlation between France, which is upwind of Illmitz, and countries downwind. This is observed for certain countries, e.g. Hungary and Czechoslovakia, but not for Romania. Other visual plots give similarly ambiguous pictures.

In short, the variance-covariance matrices of three receptors do not reveal a simple method for generalizing covariance, though further analysis may reveal the sought after explanation. But at this point we change our tactics and ask, what do we lose by simply neglecting covariance? To address this question we compare estimates of $\sigma_{d_{j}}$ with, and without, covariance. For each receptor we first compute $\sigma_{d_{j}}$ due to the two largest contributing countries. We then add the next largest contributor, and so on, until we have computed the $\sigma_{d_{j}}$ for the 10 largest contributing countries. We express our results in Fig. 10 as a ratio.

$$
\theta=\frac{\sigma_{d_{j}}(\text { computed with covariance) }}{\sigma_{d_{j}}(\text { computed without covariance) }} .
$$

For Illmitz, $\theta$ is initially 1.1 , i.e. the error estimate of deposition would be $10 \%$ larger if covariance is taken into account rather than neglected. Note that after about five to seven countries are added together, this ratio smooths out. A similar trend is found for the other receptors. From this diagram, we conclude the following. 


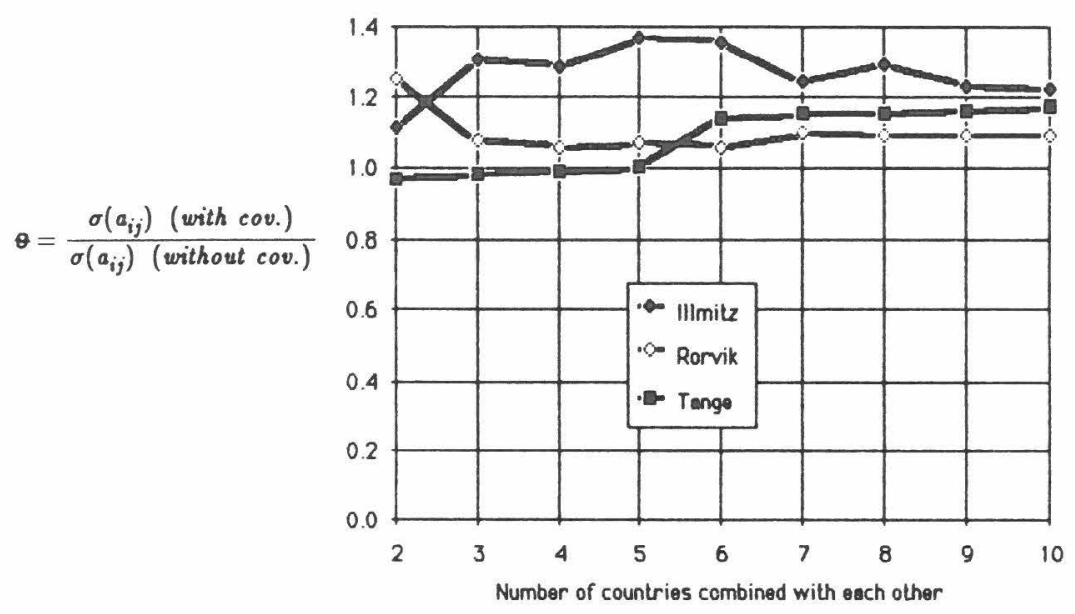

Fig. 10. Ratio between uncertainty of deposition computed with and without covariance between transfer coefficients.

TOTAL SULFUR DEPOSITION $\left(g m^{-2} y r^{-1)}\right.$

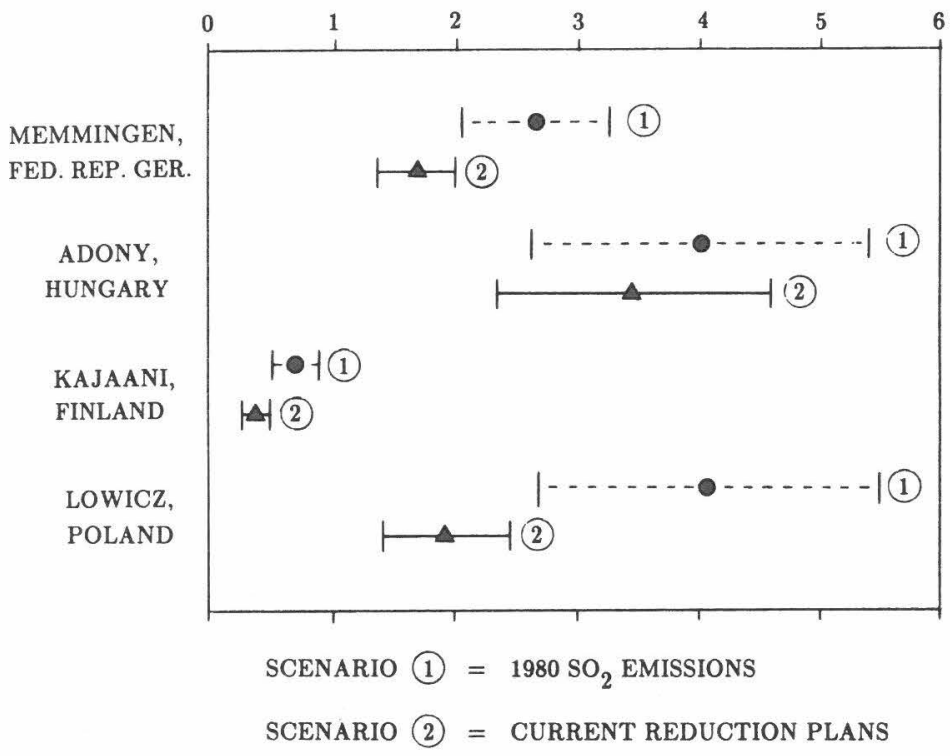

Fig. 11. Uncertainty of computed deposition at various locations in Europe.

(1) A reasonable estimate of the effect of covariance on the error estimate of deposition can be accomplished by accounting for emissions from the 10 largest contributing countries.

(2) For the three receptors, $\theta$ is relatively small, from 1.090 to 1.225 .

Routine estimates of uncertainty. Based on the preceding analysis, we now propose a method to compute the error of deposition. To account for covariance, we propose a pragmatic and tentative solution, i.e. to scale up the estimated error without covariance (Equation (2)) by the ratio $\theta^{2}$, where we assign $\theta=1.2$. With this assumption, and by substituting Equation
(4) into Equation (2), we obtain:

$$
\sigma_{d j}^{2}=0.074 \sum_{i} S_{i}^{2} a_{i j}^{2} .
$$

We can now use Equation (1) to calculate deposition, and Equation (5) to calculate the error of this deposition. Figures 11 and 12 show two ways to express this uncertainty. Both of these calculations assume that the frequency distribution of deposition is normally distributed. [For contributions of single countries to a receptor, frequency distributions approach normality (Fig. 3). When several countries contribute to a receptor we expect the distribution to be even closer to normal.] 
In Fig. 11 we depict the computed $95 \%$ confidence interval around deposition at several locations. Two scenarios are compared-a reference case of 1980 emissions and an emission reduction scenario in which emissions are reduced according to currently stated policy in each country (Table 3). Because reduction vary from 0 to $70 \%$, the European emission pattern of the Current Reduction Plans scenario is very different from the 1980 pattern. Note that the magnitude of uncertainty is both location and scenario-dependent.

Figure 12 portrays another way to express uncertainty, this time as confidence intervals around computed deposition isolines. Again the spatial dependence of the uncertainty can be observed.

Figures 11 and 12 provide an opportunity to assess the reliability of emission reduction scenarios in accomplishing deposition reductions while taking into account the uncertainty of atmospheric models. Since there is no overlap in the confidence intervals at locations in F.R.G., Finland and Poland in Fig. 11, nor in the northern or central part of Europe in Fig. 12, we are confident that the Current Reduction Plans will show a decrease in deposition at these locations. However, in areas where confidence intervals overlap (e.g. Adony, Hungary, in Fig. 11), we are less confident that the Current Reduction Plans will reduce depos- ition; if the uncertainty estimates of the two scenarios are uncorrelated then there will be only a small difference between their results, but if they are correlated there will be a significant difference between their results. This idea of correlated uncertainties is illustrated in Fig. 13, which depicts a theoretical cross-section of the overlapping isolines is Fig. 12. Assume that Scenario $\mathrm{A}$ has a deposition error of $A^{\prime}$, to the right of the mean $\bar{A}$. If errors between Scenarios A and B are correlated, then Scenario B will also have a deposition error to the right of the mean $\left(B_{2}^{\prime}\right)$; if they are uncorrelated Scenario $B$ can have an error anywhere between $B_{2}^{\prime}$ and $B_{1}^{\prime}$. In other words, if the uncertainty of two scenarios are correlated then a reduction scenario will show an improvement everywhere even if the confidence intervals of the two scenarios overlap. An example of this is a uniform $30 \%$ reduction in emissions relative to 1980 in every European country. Even though confidence intervals of deposition overlap in this case, our intuition tells us that deposition improvement will be observed everywhere (excluding the effect of interannual meteorological variability). However, for the case of the two scenarios illustrated in Figs 11 and 12, we have found their errors to be uncorrelated by comparing the residuals of their deposition computations (Fig. 14). Consequently, we are

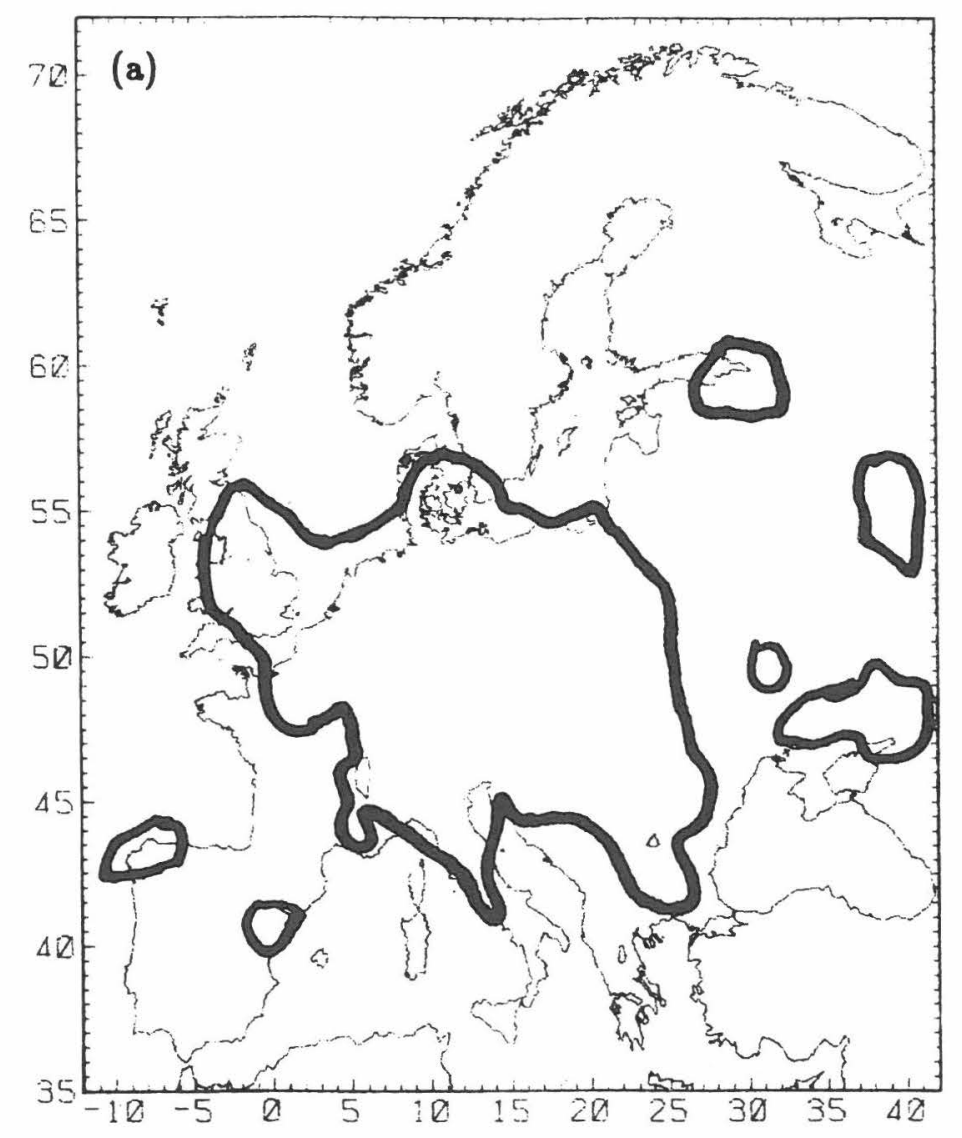

Fig. 12(a). 

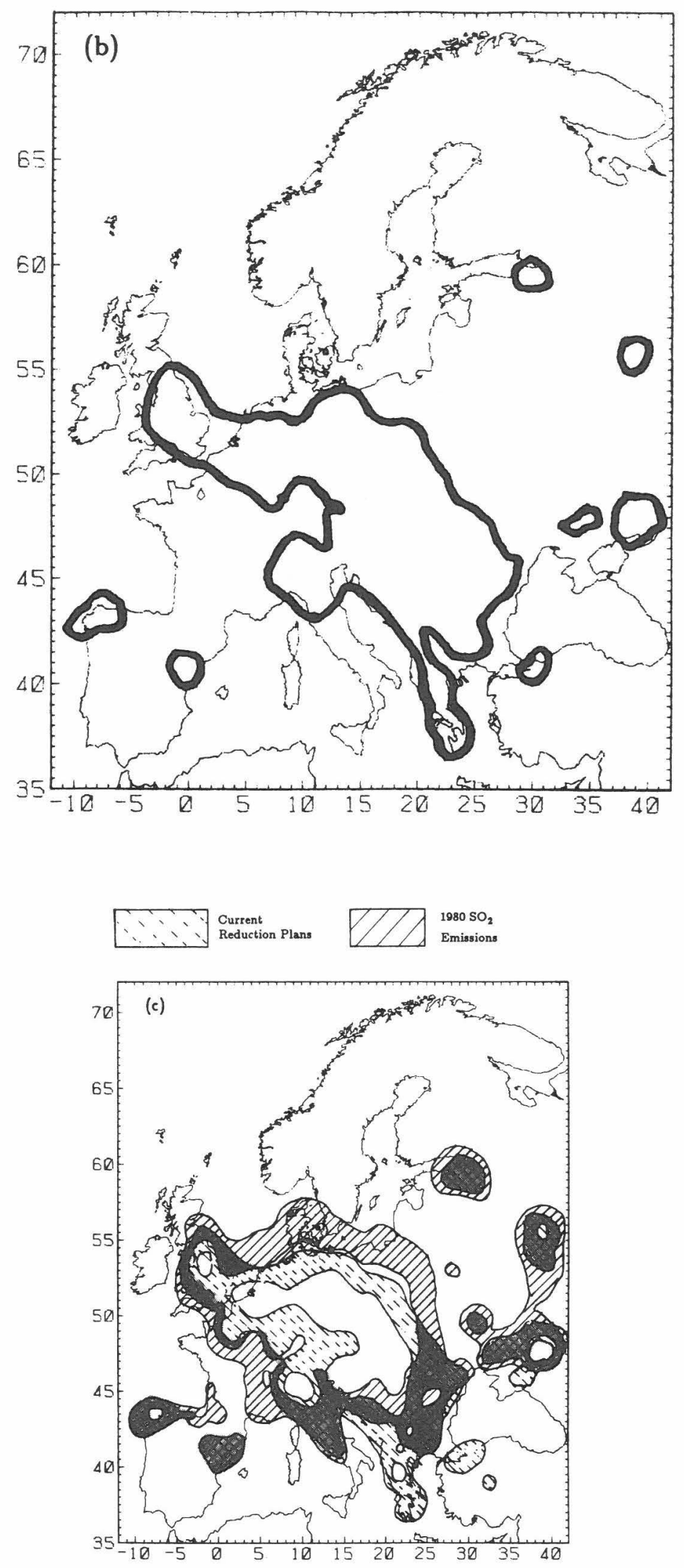

Fig. 12. (a) Computed isoline of $2 \mathrm{~g} \mathrm{~m}^{-2} \mathrm{yr}^{-1} \mathrm{~S}$ deposition for $1980 \mathrm{SO}_{2}$ emissions, (b) same as (a), but for Current Reduction Plan, (c) comparing the two scenarios with their $95 \%$ confidence ranges. 
Table 3. Current Reduction Plans for $\mathrm{SO}_{2}$ (compared to 1980 levels) from Amann (pers. comm.)

\begin{tabular}{lll}
\hline $0 \%$ & $\begin{array}{l}\text { Albania } \\
\text { Greece } \\
\text { Iceland } \\
\text { Ireland }\end{array}$ & $\begin{array}{l}\text { Portugal } \\
\text { Romania } \\
\text { Spain } \\
\text { Turkey } \\
\text { Yugoslavia }\end{array}$ \\
& Belgium & Italy \\
& Liechenstein \\
$30 \%$ & Bulgaria & U.K. \\
& C.S.S.R. & U.S.S.R. \\
& G.D.R. & \\
& Hungary & Norway \\
& Denmark & The Netherlands \\
$50 \%$ & Finland & Switzerland \\
& France & \\
$60 \%$ & Luxembourg & Sweden \\
$65 \%$ & F.R.G. & \\
$70 \%$ & Austria & \\
\hline
\end{tabular}

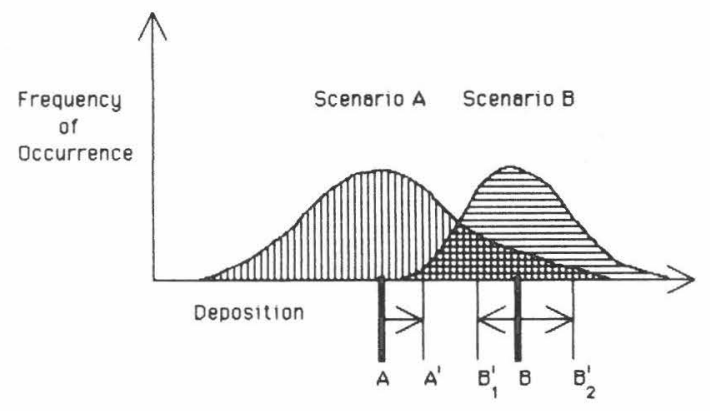

Fig. 13. Illustration of the idea of correlated and uncorrelated uncertainties of two scenarios.

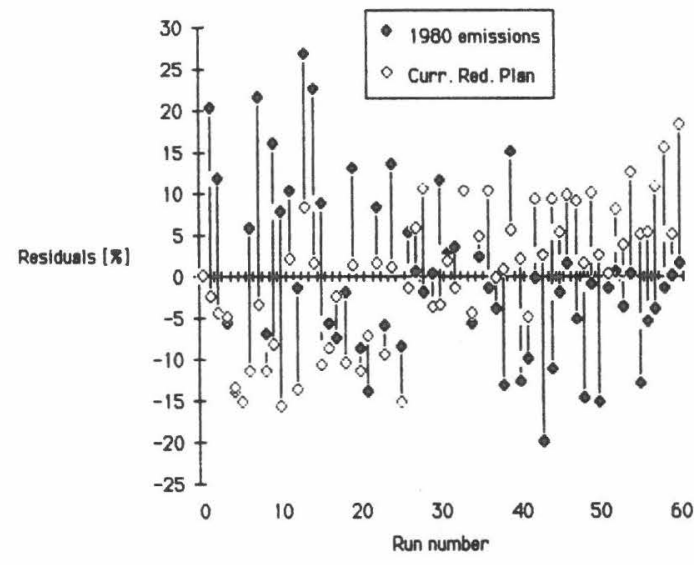

Fig. 14. Residuals of deposition at Illmitz for 60 computer runs and two scenarios.

doubtful that there will be a statistically significant difference between the two scenarios in the overlap areas of Figs 11 and 12. Put in other words, if we take into account atmospheric model uncertainty, we are not certain that Current Reduction Plan will accomplish a reduction in deposition in all parts of Europe. Of course, since mass is conserved by the model we are certain to see an improvement in deposition in Europe as a whole.

\section{DISCUSSION}

The foregoing analysis raises the question, how accurate are the theoretical uncertainty estimates? While it sounds contradictory to inquire about the accuracy of 'uncertainty' estimates, it is possible to gain insight into this question by comparing 'theoretical' uncertainty estimates (computed by the stochastic simulation procedure described in this paper) with 'observed' uncertainty estimates (calculated as the difference between measurements and mean model calculations). As an example, an estimate of the theoretical uncertainty of wet deposition (Fig. 4) is $18-25 \%$ (coefficient of variation), depending on location. For comparison, an estimate of observed uncertainty can be obtained from the plot of measured wet $\mathrm{SO}_{4}$ deposition vs model calculations presented in Lehmhaus et al. (1986). (The model version in Lehmhaus et al. (1986) is similar to the version analyzed in this paper.) From this plot we computed the mean relative deviation of model calculations from measurements, i.e. 'observed' model uncertainty, to be approximately $34 \%$. Hence, the observed model uncertainty is somewhat higher than theoretical uncertainty estimates, though still of the same magnitude. Observed model uncertainty was expected to be higher than theoretical uncertainty because, as pointed out in section 2.1 , certain sources of uncertainty are not included in the theoretical estimates. Another possible reason why theoretical and observed estimates do not agree is that theoretical estimates of wet deposition uncertainty are only available from three stations, which may or may not be representative of other locations.

The above discussion focused on wet deposition. However, one of the authors has also compared theoretical and observed uncertainty estimates for total (wet plus dry) deposition. Using Equation (5) from this paper, Alcamo (1990) computed the mean theoretical uncertainty of total deposition at 15 forest locations in Europe to be $14.8 \%$ (coefficient of variation). $\mathrm{He}$ computed the mean observed uncertainty to be slightly larger at $21.7 \%$ (mean relative deviation).

These preliminary comparisons between theoretical and observed uncertainty estimates do not provide enough evidence to confirm the results of the mathematical uncertainty analysis. Nevertheless, the order of magnitude agreement between these estimates for both wet and total deposition indicates that the results of mathematical uncertainty analysis are consistent with current knowledge about the magnitude of model error. [It should be pointed out that anonymous reviewers of this paper felt that estimates of theoretical uncertainty were too low-it can be seen now that 
theoretical estimates are not very much lower than the observed uncertainty.]

One may ask at this point, if it is possible to compute the 'observed' uncertainty as the deviation of model calculations from measurements why bother to compute the theoretical uncertainty by mathematical uncertainty analysis? Among the most important reasons are, first, mathematical uncertainty analysis allows us to analyze the relative importance of different kinds of uncertainty on model output. Second, as pointed out in the beginning of this paper, mathematical uncertainty analysis can also be used to identify the uncertainty of individual source-receptor relationships (e.g. the uncertainty of transfer coefficients). It would be difficult, if not impossible, to obtain this information by comparing model output to observations at individual locations. Knowing the uncertainty of source-receptor relationships, we can then compute the uncertainty of future deposition scenarios under changed levels of emissions - as we did in the preceding section of this paper.

Although the mathematical uncertainty analysis described in this paper can provide useful results, it has many limitations that should be addressed by further research. Among its more important limitations is the flexibility allowed in prescribing the input distributions that are then used to produce output uncertainties. Research should be devoted to reducing this arbitrariness. Where possible, these input uncertainties should be scientifically justified as we have partly done in Appendix B. Where this is impossible, different assumptions for input distributions should be tried (see, e.g. Alcamo and Bartnicki, 1987). Ultimately, however, prescribing input frequency distributions is no less scientific than the typical way in which values are assigned to model parameters based on available knowledge. Prescribing input distributions rather than discrete input values is simply an admission of the uncertainty of these inputs.

Another limitation is the use of only three receptors to derive the information in this paper. While a greater number and variety of receptors would be desirable, it is also true that the 10 source countries with three receptors gave a rich variety of source-receptor relationships representing many different geographic and meteorological situations in Europe. This adds validity to our generalization of results from 30 source-receptor combinations to all Europe. Also, uncertainty estimates in this paper only refer to 1980 meteorological conditions, though there is no evidence that they should not apply to other meteorological conditions as well. Nevertheless, other meteorological years should be studied and the effects of interannual meteorological variability should be compared with the uncertainties found in this paper.

As a final comment, we should also note that the methods gutlined in this paper can also be applied to the calculation of $\mathrm{SO}_{2}$ concentration which can be important for some environmental assessment calculations.

\section{CONCLUSIONS}

(1) The relative importance of different sources of uncertainties (transport wind, meteorological forcing functions, parameters, spatial distribution of emissions) varied greatly from receptor to receptor. Nevertheless, for all receptors the importance of meteorological forcing functions was small because they are input at short intervals compared to the annualaveraging of model output. The composite uncertainty of total (wet plus dry) deposition ranged from 10 to $20 \%$. This was, in all cases, less than the sum of individual uncertainties and indicated a compensation of errors.

(2) Of the different state variables, dry deposition, air concentration of $\mathrm{SO}_{4}^{2-}$ and wet deposition had the greatest uncertainty. The uncertainty of total (wet plus dry deposition) was less than the sum of wet plus dry deposition uncertainties, again indicating some compensation in errors.

(3) No relationship was found between distance and the relative uncertainty (coefficient of variation) of transfer coefficients; relative uncertainty neither increased nor decreased between 100 and $2000 \mathrm{~km}$ downwind of emission sources.

(4) A significant correlation was found between the absolute uncertainty (standard deviation) of transfer coefficients and distance downwind of receptors. The $\log$ of the absolute error linearly decreases with the log of distance. An even more significant correlation was found between absolute error of the transfer coefficiets and the magnitude of transfer coefficients. Using this insight, we derived a simple method for computing the standard deviation of deposition which requires only estimates of country emissions and transfer coefficients. Transfer matrices can now be used to not only compute deposition due to different emission scenarios, but also the uncertainty of this computation.

(5) A general conclusion of research presented in this paper, as well as the authors' previous work, is that the uncertainty is not large for linear models if the input errors are not strongly biased and spatial and temporal scales are large. This is consistent with the view of Geoffrey Chew that in physics 'a high degree of complexity ... can end up averaging out in such a way that it produces effective simplicity.'

Acknowledgements-The authors are grateful to A. Eliassen and J. Saltbones of the EMEP Synthesizing Center-West for providing data needed for this study. The input distributions described in Appendix B were selected, in part, based on advice received at an IIASA review meeting attended by $A$. Cocks, A. Eliassen, A. Holtslag, W. Klug, S. Pitovranov, J. Saltbones, J. den Tonkelaar and M. Uliasz. The authors are grateful for their assistance. We also wish to thank B. Lübkert, M. Posch and R. Shaw for reviewing this manuscript, and W. Schöpp for assisting with statistical analyses. 


\section{REFERENCES}

Alcamo J. (1988) Uncertainty of forecasted sulfur deposition due to uncertain spatial distribution of $\mathrm{SO}_{2}$ emissions. In Air Pollution Modelling and Its Applications VI (Edited by van Dop H.), pp. 283-292. Plenum Press, New York.

Alcamo J. (1990). Testing uncertainty estimates. (In preparation.)

Alcamo J., Amann M., Hettelingh J.-P., Holmberg M. Hordijk L., Kämäri J., Kauppi L., Kauppi P., Kornai G. and Mäkelä A. (1987) Acidification in Europe: a simulation model for evaluating control scenarios. Ambio 16, 232-245.

Alcamo J. and Bartnicki J. (1987) A framework for error analysis of a long range transport model with emphasis on parameter uncertainty. Atmospheric Environment 21, 2121-2131.

Alcamo J. and Posch M. (1986) Effect of interannua meteorological variability on computed sulfur deposition in Europe. In Atmospheric Calculations to Assess Acidification in Europe: Work in Progress (edited by Alcamo J. and Bartnicki J.), Research Report RR-86-5. International Institute for Applied Systems Analysis, A-2361, Laxenburg, Austria.

Amble E. (1981) Estimation of the spatial distribution of the population and the $\mathrm{SO}_{2}$ emissions in Europe and Turkey within the EMEP grid. NILU Report 8/81, Norwegian Institute for Air Research, P.O. Box 130, N-2001, Lillestrøm, Norway.

Beck B. (1987) Water quality modeling: a review of the analysis of uncertainty. Wat. Res. Res. 23, 1393-1442.

Dennis R. L. (1985) Issues, design and interpretation of performance evaluations: ensuring the emperor has clothes. In Air Pollution Modeling and Its Application $V$ (edited by de Wispelaere C., Schiermeier F. A. and Gillani N. V.), pp. 411-424.

Derwent R. G. (1987) Treating uncertainty in models of the atmospheric chemistry of nitrogen compounds. Atmo spheric Environment 21, 1445-1454.

Derwent R. G. and Hov Ø. (1987) The application of sensitivity and uncertainty analysis techniques to a photochemical ozone model. Harwell Report AERE-R-12615, Harwell Envir. Sciences Div., Oxfordshire, OX11 ORA, U.K.

Dovland H. and Saltbones J. (1978) Emissions of sulfur dioxide in Europe in 1978. EMEP/CCC Report 2/79, Norwegian Institute for Air Research, P.O. Box 130, N2001, Lillestrøm, Norway.

Dovland H. and Saltbones J. (1986) Emissions of sulfur dioxide in 1980 and 1983. EMEP/CCC Report 1/86, Norwegian Institute for Air Research, P.O. Box 130, N2001, Lillestrøm, Norway.

Eliassen A. (1978) The OECD study of long range transport of air pollutants: long range transport modeling. Atmospheric Environment 12, 479-487.

Eliassen A., Hov O., Ivensen J., Saltbones J. and Simpson D. (1988) Estimates of airborne transboundary transport of sulphur and nitrogen over Europe. EMEP/MSC-W Report $1 / 88$.

Eliassen A. and Saltbones J. (1983) Modeling of long range transport of sulfur over Europe: a two year model run and some model experiments. Atmospheric Environment 17, 1457-1473.

Högstrom G. (1979) Initial dry deposition and type of source in relation to long distance transport of air pollutants. Atmospheric Environment 13, 295-301.

Hordijk L. (1986) Towards a targetted emission reduction in Europe. Atmospheric Environment 20, 2053-2058.

Joffre S. (1986) Dynamical and aerodynamical factors affecting dry deposition and concentration of trace gases over the sea. In Atmospheric Computations to Assess Acidification in Europe: Work in Progress (edited by Alcamo J. and Bartnicki J.), Research Report RR-86-5. International
Institute for Applied Systems Analysis, A-2361, Laxenburg, Austria.

Lehmhaus J., Saltbones J. and Eliassen A. (1986) A modified sulfur budget for Europe for 1980. Unpublished report of the EMEP Meteorological Synthesizing Center, West, Norwegian Meteorological Institute, Oslo. EMEP/MSCW Report $1 / 86$

Mason C. and Moses H. (1984) Meteorological instrumentation. In Atmospheric Science and Power Production. (edited by Randeson D.). U.S. Department of Energy, National Technical Information Service, U.S. Department of Commerce, Springfield, VA, U.S.A.-22161.

McKay M. D., Beckman R. J. and Conover W. J. (1979) A comparison of three methods for selecting values of input variables in the analysis of output from a computer code. Technometrics 21, 239-245.

Munn R. E., Alcamo J. and Federov V. (1987) Evaluating the performance of air quality models in a policy framework. In Air Pollution Modeling and its Application VI (edited by van Dop H.), pp. 227-258. Plenum Press, New York.

Niemann (1988) Climatologic variability in computed sulfur deposition. Wat. Air Soil Pollut. 40, 79-94.

Nordlund G. (1986) Local deposition of sulfur: a comparison of Finnish estimates and EMEP model values. In Atmospheric Computations to Assess Acidification in Europe: Work in Progress (edited by Alcamo J. and Bartnicki J.), Research Report RR-86-5. International Institute for Applied Systems Analysis, A-2361, Laxenburg, Austria

OECD (Organization for Economic Co-operation and Development). The OECD Programme on Long Range Transport of Pollutants, 2nd Ed. OECD, Paris.

Pettersen S. (1956) Weather Analysis and Forecasting. McGraw-Hill, New York.

Shaw R. W. (1986) A proposed strategy for reducing sulphate deposition in North America, II. Methodology for minimizing costs. Atmospheric Environment 20, 201-206.

Streets D. G., Lesht B. M., Shannon J. D. and Veselka T. D. (1985) Climatologic variability: effect on strategies to reduce acid deposition. Envir. Sci. Technol. 19, 887-893.

\section{APPENDIX A: EMEP SULFUR TRANSPORT MODEL}

The so-called EMEP-II model is a new version of the trajectory model described in Eliassen (1978) and Eliassen and Saltbones (1983). In the latter reference, the theoretical formulation of the EMEP-II model can be found. More technical details about this model are included in Lehmaus et al. (1986) and Eliassen et al. (1988). The basic equations, integrated along a trajectory, have the following form:

$$
\begin{aligned}
& \frac{\mathrm{D} q}{\mathrm{~d} t}=-\left(\frac{v_{\mathrm{d}}}{h}+k_{\mathrm{t}}+k_{\mathrm{w}, \mathrm{q}}\right) \cdot q+E_{\mathrm{q}}+(1-\alpha-\beta) \frac{Q}{h} \\
& \frac{\mathrm{D} s}{\mathrm{~d} t}=-\left(\frac{w_{\mathrm{d}}}{h}+k_{\mathrm{w}, \mathrm{s}}\right) \cdot s+E_{\mathrm{s}}+k_{\mathrm{t}} \cdot q+\beta \frac{Q}{h}
\end{aligned}
$$

where:

$q=\mathrm{SO}_{2}$ concentration at the receptor point

$s=\mathrm{SO}_{4}^{2-}$ concentration at the receptor point

D

$\frac{\mathrm{d}}{\mathrm{d} t}=$ total time derivative

$E_{\mathrm{q}}, E_{\mathrm{s}}=$ flux of $\mathrm{SO}_{2}$ and $\mathrm{SO}_{4}^{2-}$, respectively, from free troposphere

$Q=$ sulfur emission per unit area and time

Other symbols responsible for different physical processes are explained in Table A-1 and in more detail below. Backward $96 \mathrm{~h}$ trajectories are calculated using the method described by Pettersen (1956) and $850 \mathrm{hPa}$ wind data updated every $6 \mathrm{~h}$. 
Variable mixing height. In the EMEP-II model, mixing height is variable in time and space. Objectively analyzed mixing height is taken every $24 \mathrm{~h}$ at $1200 \mathrm{GMT}$. Based on this information and on estimated vertical velocity, a new value of the mixing height can be computed:

$$
h(t)=h_{1}+\int_{t_{1}}^{t} w\left(t^{\prime}\right) \mathrm{d} t^{\prime}
$$

where $w$ is the vertical velocity at the top of air parcel.

$$
w=\sqrt{\frac{2 K}{f}} \sin \gamma \cos \gamma \zeta_{\mathrm{g}}
$$

where $\zeta_{\mathrm{g}}$ is geostrophic vorticity approximated by vorticity of $850 \mathrm{hPa}$ advection wind, $\gamma=20^{\circ}$ is the cross-isobaric angle, $f$ $=$ Coriolis parameter, and $K$ is the turbulent diffusivity for vertical momentum transport:

$$
K=0.4 u_{*} z_{\mathrm{p}} ; z_{\mathrm{p}}=50 \mathrm{~m}
$$

where $u_{*}$ can be estimated from the observed surface wind:

$$
\frac{u\left(z_{3}\right)}{u_{*}}=\frac{1}{\kappa} \ln \frac{z_{3}}{z_{3}}
$$

where $\kappa$ is the von Karman constant, $z_{3}=10 \mathrm{~m}, z_{0}$ is roughness parameter.

Exchange of pollutants between boundary layer and free troposphere. This process, described in Equations (A.1), (A.2) by terms $E_{\mathrm{q}}$ and $E_{\mathrm{s}}$, can be taken into account in the following way: knowing the value of the mixing height at time $t_{1}$ we can compute mixing height $24 \mathrm{~h}$ later at time $t_{2}$ by means of Equation (A.3). Denoting this mixing height by $h\left(t_{2}\right)$ we can compare it with the objectively analyzed value of the mixing height $h_{2}$. If $h\left(t_{2}\right)>h_{2}$ then the sulphur dioxide is kept unchanged. If $h\left(t_{2}\right)<h_{2}$, then the concentration due to anthropogenic emission $q_{\mathrm{a}}$ is diluted in proportion to $h\left(t_{2}\right) / h_{2}$. This results in a new sulphur dioxide concentration:

$$
q_{2}=\frac{h\left(t_{2}\right)}{h_{2}} q_{\mathrm{a}}+q_{\mathrm{b}}
$$

where $q_{\mathrm{b}}$ is a background concentration in the free troposphere. The same procedure is applied to $\mathrm{SO}_{4}^{2-}$ concentration.

Deposition velocities. The deposition velocity for $\mathrm{SO}_{2}$ is calculated in two steps. Firstly, deposition velocity at $1 \mathrm{~m}$ is computed

$v_{\mathrm{d}}(1 \mathrm{~m})=\left\{\begin{array}{l}a_{1}(\tau) v_{\mathrm{d} 1}(t)+a_{2}(\tau) v_{\mathrm{d} 2} \tan \left(\frac{1}{2}\left(\frac{\pi}{2}-\varphi\right)\right) \text { over land } \\ c_{\mathrm{v}, \text { sea }} \text { over sea }\end{array}\right.$

where $\tau$ is the time of the year, $t$ the diurnal time, $\varphi$ the geographical latitude and:

$$
a_{1}(\tau)+a_{2}(\tau)=1
$$

$v_{\mathrm{d} 1}=\left\{\begin{array}{l}v_{\mathrm{d} 1, \mathrm{day}}-\text { day }(0400-2200 \mathrm{LT}) \\ v_{\mathrm{d} 1, \text { night }}-\text { night } .\end{array}\right.$

Second, the deposition velocity at $50 \mathrm{~m}$ is calculated:

$$
v_{\mathrm{d}}(50 \mathrm{~m})=v_{\mathrm{d}}(1 \mathrm{~m})\left[1+\frac{v_{\mathrm{d}}(1 \mathrm{~m})}{k^{2} u(10 \mathrm{~m})} \ln 50 \cdot \ln \frac{10 \mathrm{~m}}{z_{0}}\right]^{-1} \text {. }
$$

Deposition velocity for $\mathrm{SO}_{4}^{2-}$ has a constant value:

$$
w_{\mathrm{d}}=0.1 \mathrm{~m} \mathrm{~s}^{-1} \text {. }
$$

Transformation rate $\mathrm{SO}_{2}$ to $\mathrm{SO}_{4}^{2-}$. The transformation rate $k_{\mathrm{t}}$ is calculated as follows:

$$
k_{\mathrm{t}}(\tau)=k_{10}+k_{\mathrm{t} 1} \sin \left(2 \pi \frac{\tau}{T}+\theta\right)
$$

\begin{tabular}{|c|c|c|}
\hline Symbol & Definition & Value \\
\hline$v_{\mathrm{d}}$ & Deposition velocity for $\mathrm{SO}_{2}$ & Variable \\
\hline$v_{\mathrm{d} 1 \text {, day }}$ & $\begin{array}{l}\text { Deposition velocity for } \mathrm{SO}_{2} \text { over the land } \\
\text { during the day }\end{array}$ & $0.008 \mathrm{~m} \mathrm{~s}^{-1}$ \\
\hline$v_{\mathrm{d} 1, \text { night }}$ & $\begin{array}{l}\text { Deposition velocity for } \mathrm{SO}_{2} \text { over the land } \\
\text { during the night }\end{array}$ & $0.002 \mathrm{~ms}^{-1}$ \\
\hline$v_{\text {d, sea }}$ & Deposition velocity for $\mathrm{SO}_{2}$ over the sea & $0.008 \mathrm{~m} \mathrm{~s}^{-1}$ \\
\hline$v_{\mathrm{d} 2}$ & $\begin{array}{l}\text { Deposition velocity for } \mathrm{SO}_{2} \text {-amplitude } \\
\text { of latitude-dependent part }\end{array}$ & $0.008 \mathrm{~m} \mathrm{~s}^{-1}$ \\
\hline$w_{\mathrm{d}}$ & Deposition velocity for $\mathrm{SO}_{4}^{2-}$ & $0.001 \mathrm{~m} \mathrm{~s}^{-1}$ \\
\hline$k_{t}$ & Transformation rate $\mathrm{SO}_{2-}>\mathrm{SO}_{4}^{2-}$ & Variable \\
\hline$k_{t 0}$ & Transformation rate-constant part & $3 \times 10^{-6} \mathrm{~s}^{-1}$ \\
\hline$k_{t 1}$ & Transformation rate-amplitude & $2 \times 10^{-6} s^{-1}$ \\
\hline$h$ & Mixing height & Variable \\
\hline$\alpha$ & $\begin{array}{l}\text { Additional local } \mathrm{SO}_{2} \text { dry deposition } \\
\text { in grid square where emission takes place }\end{array}$ & 0.15 \\
\hline$\beta$ & $\begin{array}{l}\text { Part of sulphur emission assumed to be } \\
\text { emitted as sulphate }\end{array}$ & 0.05 \\
\hline$w_{\mathrm{q}}$ & Scavenging ratio for $\mathrm{SO}_{2}$ & $2 \times 10^{5}$ \\
\hline$w_{\mathrm{s}}$ & Scavenging ratio for $\mathrm{SO}_{4}^{2-}$ & $7 \times 10^{5}$ \\
\hline$k_{\mathrm{w}, \mathrm{q}}$ & Removal rate for $\mathrm{SO}_{2}$ during rain & Variable \\
\hline$k_{\mathrm{w}, \mathrm{s}}$ & Removal rate for $\mathrm{SO}_{4}^{2-}$ during rain & Variable \\
\hline$q_{\mathrm{b}}$ & Background concentration for $\mathrm{SO}_{2}$ & $0.1 \mu \mathrm{g} \mathrm{m}^{-3}$ as $\mathrm{S}$ \\
\hline$s_{\mathrm{b}}$ & Background concentration for $\mathrm{SO}_{4}^{2-}$ & $0.2 \mu \mathrm{g} \mathrm{m}^{-3}$ as $\mathrm{S}$ \\
\hline$c_{\mathrm{b}}$ & Background concentration for $\mathrm{SO}_{4}^{2-}$ in precipitation & $0.3 \mu \mathrm{g} \ell^{-1}$ as $\mathrm{S}$ \\
\hline
\end{tabular}

where $T$ is 1 year and $\theta$ is chosen in such a way that $k_{1}$ reaches its maximum at summer solstice.

Wet deposition rate. The wet deposition rate for $\mathrm{SO}_{2}$ is given by

$$
k_{\mathrm{w}, \mathrm{q}}=\frac{W_{\mathrm{q}} P_{6}}{h}
$$

Table A-1. EMEP-II parameters and variables 
and for $\mathrm{SO}_{4}^{2-}$ by:

$$
k_{\mathrm{w}, \mathrm{s}}=\frac{W_{\mathrm{s}} \cdot P_{6}}{h}
$$

where $W_{\mathrm{q}}$ and $W_{\mathrm{s}}$ are scavenging ratios (Table A.1) and $P_{6}$ is the objectively analyzed precipitation intensity for the last $6 \mathrm{~h}$.

\section{APPENDIX B: INPUT DISTRIBUTIONS FOR TRANSPORT WIND, PARAMETERS AND METEOROLOGICAL FORCING FUNCTIONS}

In this section we describe the selection of frequency distributions of inputs to the stochastic simulation exercise. The selection of these distributions was based largely on technical considerations discussed with scientists listed in the Acknowledgements. Because of space limitations we are only able to briefly review these considerations in this section.

Wind uncertainty. As noted in the text, this distribution reflects the uncertainty of the vertical level of the mean transport wind. In Fig. B-1, we assume that the most probable transport level is wind class 4 , i.e. approximately $925 \mathrm{hPa}$. This is the level used for trajectory calculations by Eliassen et al. (1988) and is closer (than $850 \mathrm{hPa}$ ) to the elevation where maximum vertical $\mathrm{SO}_{2}$ concentrations have been measured in Europe (OECD, 1979). The distribution in Fig. B-1 also assumes that wind class $1(850 \mathrm{mb})$ has a $20 \%$ smaller probability than the most probable class. We assume that from class 4 to class 10 there is a steadily declining probability of occurrence, i.e. that there is very small chance that the mean transport wind is located near the surface. Atmospheric turbulence makes it unlikely that the mean transport wind would be very near the surface, though ground-based transport occurs intermittently.

Since there are many other possible assumptions for this input distribution, we have compared results using three different input distributions: (1) the truncated triangle in Fig. B-1 (which is described above and which we used for calculations earlier in this paper), (2) a skewed triangle with a median at class 6 (approximately $700 \mathrm{~m}$ elevation) and zero probability below class 1 and above class 10 and, (3) a uniform distribution. The skewed triangle and uniform distributions give somewhat higher deposition uncertainty estimates than the truncated triangle (for deposition at Illmitz, the c.v. $=2.52 \%, 3.18 \%$ and $3.46 \%$ for the truncated triangle, skewed triangle and uniform distribution, respectively; and for Rorvik deposition, c.v. $=5.18 \%, 5.92 \%$ and $7.92 \%$, respectively).

Although the skewed triangle and uniform input distributions give higher uncertainty estimates, we used the truncated triangle for our composite uncertainty analysis because we believe it is a fairer representation of the wind class uncertainty than the more extreme assumptions reflected in other distributions: the skewed triangle distribution assumes that there is virtually no possibility that the mean transport wind is at $850 \mathrm{hPa}$; and the uniform distribution assumes that there is an equal probability that the mean transport wind will be at any level.

Meteorological forcing functions. Assumed input distributions of forcing functions are given in Table B-1. The mixing height is estimated from four characteristic points in the boundary layer. Uncertainty of mixing height arises from measurement and interpolation (spatial and temporal) errors. Based on these considerations we assign the mixing height a triangular distribution with $\pm 50 \%$ range.

The surface wind is used to calculate the dry deposition velocity and vertical velocity (see Appendix A). To estimate the uncertainty of surface wind we note that Mason and Moses (1984) estimate that the error of horizontal wind velocity measurements is about $1-10 \%$. If we conservatively assume that the standard deviation is $10 \%$, then two standard deviations would be $20 \%$. Consequently, we assign the surface wind a triangular distribution with a $\pm 20 \%$ range.

The $850 \mathrm{hPa}$ wind is used to estimate vertical velocity (see Appendix A). One might argue that the surface wind estimate should be more accurate than the estimate of $850 \mathrm{hPa}$ wind

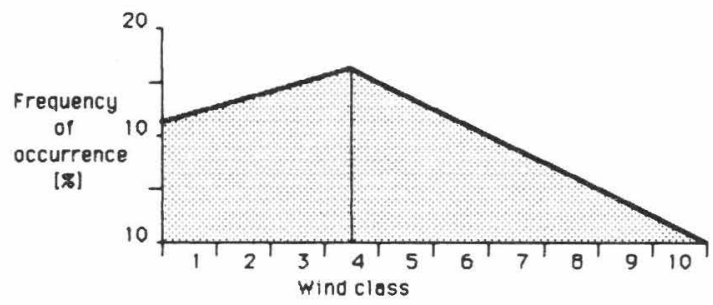

Fig. B-1. Input frequency distribution for transport wind uncertainty.

Table B-1. Input distribution assumptions

\begin{tabular}{|c|c|c|c|c|}
\hline $\begin{array}{l}\text { Forcing func- } \\
\text { tion } \\
\text { or parameter }\end{array}$ & Type & Median & Range & Units \\
\hline Mixing height & Triangle & $\begin{array}{c}\text { Meteorological } \\
\text { data base }\end{array}$ & $\pm 50 \%$ & $\mathrm{~m}$ \\
\hline Precipitation & Triangle & $\begin{array}{c}\text { Meteorological } \\
\text { data base }\end{array}$ & $\pm 50 \%$ & $\mathrm{~mm}$ \\
\hline $850 \mathrm{hPa}$ wind & Triangle & $\begin{array}{l}\text { Meteorological } \\
\text { data base }\end{array}$ & $\pm 20 \%$ & $\mathrm{~ms}^{-1}$ \\
\hline Surface wind & Triangle & $\begin{array}{c}\text { Meteorological } \\
\text { data base }\end{array}$ & $\pm 20 \%$ & $\mathrm{~ms}^{-1}$ \\
\hline$v_{\mathrm{d} 1}$-night & Triangle & 0.2 & $0.1-0.3$ & $\mathrm{~cm} \mathrm{~s}^{-1}$ \\
\hline$v_{\mathrm{d} 1}$ - day & Uniform & 0.8 & $0.65-0.95$ & $\mathrm{~cm} \mathrm{~s}^{-1}$ \\
\hline$v_{\mathrm{d} 2}$ & Triangle & 0.5 & $0.25-0.75$ & $\mathrm{~cm} \mathrm{~s}^{-1}$ \\
\hline$v_{\text {d, sea }}$ & Triangle & 0.8 & $0.1-1.2$ & $\mathrm{~cm} \mathrm{~s}^{-1}$ \\
\hline$w_{d}$ & Triangle & 0.1 & $0.0-0.3$ & $\mathrm{~cm} \mathrm{~s}^{-1}$ \\
\hline$\alpha$ & Triangle & 0.15 & $0.0-0.3$ & fraction \\
\hline$\beta$ & Triangle & 0.05 & $0.025-0.075$ & fraction \\
\hline$k_{t 0}$ & Triangle & $3.0 \times 10^{6}$ & $1.5 \times 10^{6}-4.5 \times 10^{6}$ & $s^{-1}$ \\
\hline$w_{\mathrm{q}}$ & Triangle & $2.0 \times 10^{5}$ & $0.05 \times 10^{5}-2.0 \times 10^{5}$ & - \\
\hline$w_{3}$ & Triangle & $7.0 \times 10^{5}$ & $3.5 \times 10^{5}-9.0 \times 10^{5}$ & - \\
\hline
\end{tabular}


because the former is obtained from ground instruments, whereas the latter is based on remote rawinsonde measurements. On the other hand, rawinsonde are not as affected by complex terrain as are ground instruments, and rawinsonde instrumentation is also rather advanced. Consequently, we assume that the $850 \mathrm{hPa}$ wind has the same uncertainty as surface wind.

The uncertainty of precipitation inputs arises from measurement error [in the order of 10-30\% (Mason and Moses, 1984)] and spatial and temporal interpolation of data. We represent this uncertainty as a triangular distribution with $\pm 50 \%$ range.

Parameters. Assumed input distribution for parameters are noted in Table B-1. We begin with the parameters used to compute dry deposition of $\mathrm{SO}_{2}$ in Equations A.8 and A.9. Since the parameters $v_{d 1 \text {, night }}$ and $v_{d 2}$ have approximately the same uncertainty, we assign them triangular distribution with $\pm 50 \%$ ranges. The dry deposition rate during the day, $v_{d 1 \text {, day }}$ can vary substantially owing to local topography and meteorology. We therefore assign it the same range as the other above parameters, but a uniform rather than triangle distribution.

The deposition velocity of $\mathrm{SO}_{2}$ over sea, $v_{d \text {, sea }}$, is known to have great variability (see, e.g. Joffre, 1986). We therefore set the range of this distribution rather widely as $0.1-1.2 \mathrm{~cm} \mathrm{~s}^{-1}$, with a median at 0.8 (the model value). The distribution shape is assumed to be a triangle.
The limits of the deposition velocity of $\mathrm{SO}_{4}^{2-}, w_{\mathrm{d}}$ are also assumed to be wide-from zero to three times the model value $\left(0.3 \mathrm{~cm} \mathrm{~s}^{-1}\right)$ because this parameter can have a substantial spatial and temporal variability throughout Europe.

We now turn to a related parameter, the local deposition coefficient, $\alpha$, which expresses the amount of $\mathrm{S}$ deposition that is deposited in the grid element where emissions originate. Based on estimates by Nordlund (1986) and Högstrom (1979) we assign a triangle distribution with a range of $\pm 100 \%$.

The fraction of emissions assumed to be emitted as $\mathrm{SO}_{4}^{2-}$ rather than $\mathrm{SO}_{2}, \beta$, is assigned a triangular distribution with a $\pm 50 \%$ range.

From dry deposition we now move to wet deposition where two parameters are of concern-the scavenging ratios of $\mathrm{SO}_{2}$ and $\mathrm{SO}_{4}^{2-}, w_{\mathrm{q}}$ and $w_{\mathrm{s}}$. We assume that the model value of $w_{\mathrm{q}}\left(2 \times 10^{5}\right)$ is the highest practical value for $\mathrm{SO}_{2}$ absorption by precipitation. Therefore we assign it a triangle distribution with $0.5 \times 10^{5}$ as the lower limit and $2.0 \times 10^{5}$ as the median and upper limit.

The seasonally constant part of the $\mathrm{SO}_{2}$ to $\mathrm{SO}_{4}^{2-}$ transfer rate $\left(k_{\mathrm{to}}\right)$ varies spatially according to local temperature, solar radiation and other conditions. This uncertainty is represented by a triangular distribution with a $\pm 50 \%$ range. The seasonal applitude of this transfer rate $\left(K_{t 1}\right)$ is assumed to be two-thirds of $K_{t 0}$. 


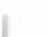



